\title{
Fermentation metabolism and its evolution in algae
}

\author{
Claudia Catalanotti ${ }^{1}$ *, Wenqiang Yang ${ }^{1}$, Matthew C. Posewitz ${ }^{2}$ and Arthur R. Grossman ${ }^{1}$ \\ 1 Department of Plant Biology, Carnegie Institution for Science, Stanford, CA, USA \\ 2 Department of Chemistry and Geochemistry, Colorado School of Mines, Golden, CO, USA
}

\section{Edited by:}

Pierdomenico Perata, Scuola

Superiore Sant'Anna, Italy

\section{Reviewed by:}

Michael Hippler, University of Muenster, Germany

Elena Loreti, Consiglio Nazionale delle Ricerche, Italy

\section{*Correspondence:}

Claudia Catalanotti, Department of Plant Biology, Carnegie Institution for Science, 260 Panama Street, Stanford, CA 94305, USA. e-mail: ccatal1@stanford.edu
Fermentation or anoxic metabolism allows unicellular organisms to colonize environments that become anoxic. Free-living unicellular algae capable of a photoautotrophic lifestyle can also use a range of metabolic circuitry associated with different branches of fermentation metabolism. While algae that perform mixed-acid fermentation are widespread, the use of anaerobic respiration is more typical of eukaryotic heterotrophs. The occurrence of a core set of fermentation pathways among the algae provides insights into the evolutionary origins of these pathways, which were likely derived from a common ancestral eukaryote. Based on genomic, transcriptomic, and biochemical studies, anaerobic energy metabolism has been examined in more detail in Chlamydomonas reinhardtii (Chlamydomonas) than in any other photosynthetic protist. This green alga is metabolically flexible and can sustain energy generation and maintain cellular redox balance under a variety of different environmental conditions. Fermentation metabolism in Chlamydomonas appears to be highly controlled, and the flexible use of the different branches of fermentation metabolism has been demonstrated in studies of various metabolic mutants. Additionally, when Chlamydomonas ferments polysaccharides, it has the ability to eliminate part of the reductant (to sustain glycolysis) through the production of $\mathrm{H}_{2}$, a molecule that can be developed as a source of renewable energy. To date, little is known about the specific role(s) of the different branches of fermentation metabolism, how photosynthetic eukaryotes sense changes in environmental $\mathrm{O}_{2}$ levels, and the mechanisms involved in controlling these responses, at both the transcriptional and post-transcriptional levels. In this review, we focus on fermentation metabolism in Chlamydomonas and other protists, with only a brief discussion of plant fermentation when relevant, since it is thoroughly discussed in other articles in this volume.

Keywords: anoxic, anaerobiosis, hypoxic, fermentation, pyruvate metabolism

\section{INTRODUCTION}

\section{Chlamydomonas AS A MODEL ORGANISM}

Chlamydomonas reinhardtii (Chlamydomonas throughout) is a soil-dwelling, unicellular green alga that is considered a model organism for studying photosynthetic energy metabolism, and the production of molecular hydrogen $\left(\mathrm{H}_{2}\right)$ under anoxic conditions (Melis and Happe, 2001, 2004; Ghirardi et al., 2007). This alga has several metabolic features in common with those of vascular plants, although it also has structures and activities (e.g., flagella and eyespot) that were lost during vascular plant evolution. Chlamydomonas represents a robust system for probing biological processes with sophisticated molecular tools. The sequencing of all three Chlamydomonas genomes (nuclear, chloroplast, and mitochondrion; Lilly et al., 2002; Maul et al., 2002; Merchant et al., 2007) has facilitated the capture of information about gene and genome structure and potential regulatory sequences, including promoter regions, $3^{\prime}$ - and $5^{\prime}$-UTRs and intron-exon junctions. Forward and reverse genetic screens have been developed to generate mutant strains with specific phenotypes, or that are disrupted for specific genes (Dent et al., 2005; Pootakham et al., 2010; Gonzalez-Ballester et al., 2011). Most information discussed in this manuscript on responses of algae to hypoxia/anoxia was derived from studies of Chlamydomonas, although information for other algae has been used to strengthen generalizations. Furthermore, we briefly discuss the evolution of the fermentation processes in prokaryotes and non-photosynthetic eukaryotes, but do not discuss plants since other contributions in this volume detail the responses of plants to hypoxic conditions.

\section{BASIC ENERGY-GENERATING PROCESSES}

Whether in aerobic or anaerobic environments, the challenge for organisms to maintain viability can only be met if they can stay far from equilibrium. To achieve this situation, they must use energy to satisfy their metabolic demands, which includes continuous synthesis of the cellular energy currency (mostly ATP) along with maintenance of redox and ionic balances. Aerobic metabolism is used by several eukaryotic and prokaryotic organisms to efficiently synthesize ATP through oxidative phosphorylation; $\mathrm{O}_{2}$ serves as the terminal electron acceptor of the respiratory electron transport chain (Bailey-Serres and Chang, 2005). Nevertheless, life in low $\mathrm{O}_{2}$ (hypoxia) environments, or even in environments totally devoid of $\mathrm{O}_{2}$ (anoxia), is common on our planet. Diminished levels of $\mathrm{O}_{2}$ in various biotopes can result from geochemical or physical conditions, including flooding, excess rainfall, and winter ice encasement, but may also be a consequence of high metabolic activity of bacteria in habitats that are not well aerated. While 
anoxia is often transient, it can also be protracted, extending from diurnal periods, to months or years, and even to millennia or more (Grieshaber et al., 1994; Burnett, 1997; Danovaro et al., 2010). Furthermore, even though an organism may live in an oxic habitat, it may still perform anoxic metabolism under certain circumstances. For example, in the presence of sufficient levels of a fermentable substrate, many yeast strains will forego using $\mathrm{O}_{2}$ as a terminal electron acceptor and maintain vigorous fermentation of available substrates (van Dijken and Scheffers, 1986; Pronk et al., 1996).

\section{REDOX BALANCE THROUGH FERMENTATION}

For cells to sustain viability during hypoxia/anoxia they must produce ATP and recycle the $\mathrm{NAD}(\mathrm{P}) \mathrm{H}$ and $\mathrm{FADH}_{2}$ generated by catabolic pathways, usually glycolysis. These compounds must be re-oxidized in a process involving the transfer of electrons to suitable terminal acceptor molecules, which are then typically secreted. Among eukaryotes, there are only two processes for maintaining redox balance and conserving energy when organisms experience anoxic conditions: (i) fermentation, which usually entails substrate-level phosphorylation (SLP), and (ii) anaerobic respiration which involves terminal electron acceptors like $\mathrm{NO}_{3}^{-}$ and $\mathrm{SO}_{4}^{2-}$ instead of $\mathrm{O}_{2}$ (Atteia et al., 2013). Anaerobic metabolism provides cells with low levels of chemical bond energy, generating 2-3 ATP molecules per molecule of glucose metabolized; this compares to the over 30 ATP molecules generated by the oxidative metabolism of glucose.

\section{METABOLIC ENERGY GENERATION INTRODUCTORY REMARKS}

Glycolysis oxidizes glucose to two molecules of pyruvate while generating two ATP molecules. During the oxidation of glucose there is also the production of two NADH molecules (four reducing equivalents). To maintain glycolytic flux and energy production, the cells must re-oxidize the NADH. In the absence of a functional TCA cycle under anaerobic conditions, Chlamydomonas places reducing equivalents into partially oxidized metabolic intermediates. The following section reviews the main anaerobic pathways activated in many organisms, including prokaryotic bacteria, eukaryotic fungi, and animals, when they are exposed to hypoxic/anoxic conditions.

\section{IN BACTERIA (Figure 1)}

In the absence of $\mathrm{O}_{2}$ and under conditions that favor catabolite repression (e.g., excess glucose), Escherichia coli does not utilize a complete TCA cycle. However, it can use enzymes of this cycle to synthesize succinyl-CoA and 2-oxoglutarate; these metabolites represent the reductive and oxidative branches of the TCA cycle, respectively (Wolfe, 2005). This branched form of the TCA cycle does not generate energy but instead provides the precursor metabolites needed for cell viability. Therefore, ATP must come from glycolysis and SLP is associated with the phosphotransacetylase-acetate kinase pathway (Brown et al., 1977).

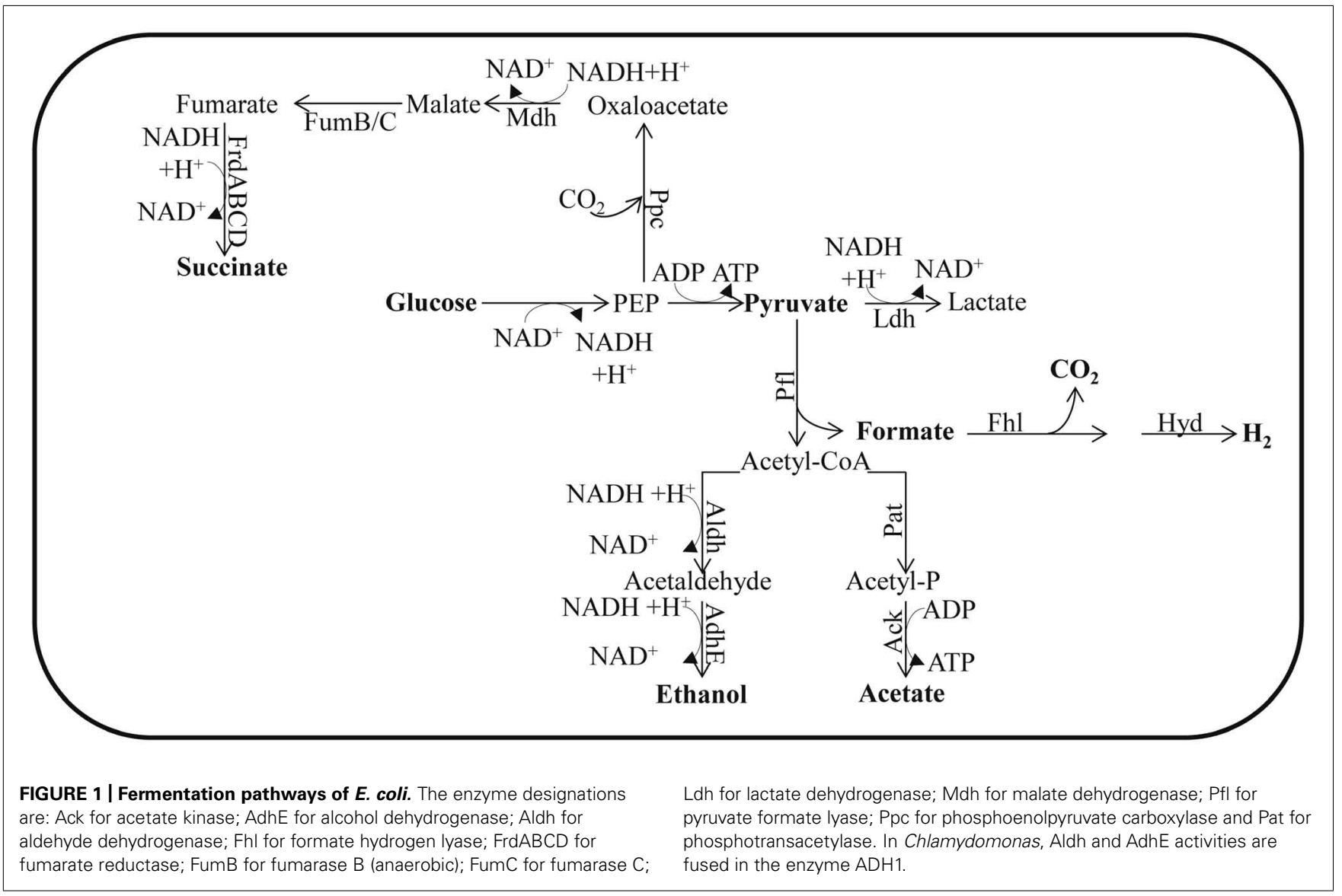


To sustain the flow of glycolytic metabolites when $\mathrm{O}_{2}$ availability severely limits aerobic respiration, the cells must re-oxidize $\mathrm{NADH}$. In many bacteria the sugars are fermented to a mixture of ethanol and organic acids. This is achieved by reducing partially oxidized metabolic intermediates and forming, predominantly, the metabolites D-lactate, succinate, and ethanol, which are excreted into the environment along with formate and acetate (Wolfe, 2005; Figure 1). During anaerobiosis, pyruvate is the major metabolite synthesized as a consequence of glycolysis. The pyruvate can be converted to formate and acetylcoenzyme A (acetyl-CoA) by pyruvate formate lyase (Pfl; Wolfe, 2005; Figure 1). This conversion is a non-oxidative reaction, which contrasts with oxidative decarboxylation that is mediated by the pyruvate dehydrogenase complex (Pdh, also sometimes designated Pdhc), which functions during respiratory metabolism. Pfl and its activating enzyme are widespread in facultative and obligate anaerobic eubacteria, as well as in archaea (Sawers and Watson, 1998). Mutants of E. coli devoid of Pfl do not grow anaerobically on glucose, but can grow if the medium is supplemented with acetate (Varenne et al., 1975). Under such conditions, pfl mutants maintain glycolytic ATP synthesis by reducing pyruvate to lactate. The generation of an $l d h$ mutant in the $p f l$ strain eliminates the remaining fermentation pathway for sustaining glycolysis. The formate derived from the Pfl reaction may be further metabolized to $\mathrm{H}_{2}$ and $\mathrm{CO}_{2}$ through the activity of formate hydrogen lyase (Fhl; Gottschalk, 1985) while the acetyl-CoA generated in this reaction can be converted to acetate or reduced to ethanol. Full conversion of acetyl-CoA to ethanol would not allow for redox balance since a single $\mathrm{NADH}$ is generated for each pyruvate that is synthesized from sugars, and two NADH molecules are required to convert pyruvate to ethanol. In order to achieve redox balance, E. coli must also synthesize additional products from the pyruvate, such as acetate and/or succinate (Dien et al., 2003).

The type and amount of fermentation end products excreted by bacteria, and the level of NADH generated for recycling, are highly dependent upon the substrate being metabolized by the bacterium. For example, bacteria using sorbitol, a highly reduced carbon compound, produce three NADH molecules per molecule of substrate, while a highly oxidized carbon compound such as glucuronic acid generates no NADH. To regenerate $\mathrm{NAD}^{+}$from the NADH formed during the oxidation of sorbitol, bacteria synthesize and excrete ethanol (Wolfe, 2005). In contrast, cells growing on glucuronic acid are redox balanced and therefore no ethanol will be synthesized; instead, most pyruvate will be converted to acetate (Alam and Clark, 1989). The composition of excreted fermentation products also depends on the oxidation state of the cells and the $\mathrm{pH}$ of the medium. At neutral or higher $\mathrm{pH}$, the main end products are acetate, ethanol, and formate, with moderate levels of succinate (Belaich and Belaich, 1976). However, as the $\mathrm{pH}$ becomes more acidic, cells produce lactate instead of acetate and formate (Bunch et al., 1997).

The conversion of acetyl-CoA to acetate is catalyzed by the phosphoacetyltransferase-acetate kinase (Pat-Ack also known as Pta-AckA) pathways. The Pat-Ack pathway generates one ATP per molecule of pyruvate metabolized, but consumes no NADH (Figure 1). In contrast, reduction of acetyl-CoA to ethanol is catalyzed by the bifunctional acetaldehyde/alcohol dehydrogenase (AdhE). While this reaction consumes reducing equivalents, it does not result in the generation of ATP (Wolfe, 2005). By coordinating the amount of ethanol and acetate (and other organic acids) synthesized and excreted into the medium, bacteria can efficiently balance their energy requirement with the need to recycle redox carriers (as reviewed by Wolfe, 2005).

There are two major acetate-producing pathways in E. coli; these are pyruvate oxidase (PoxB) and Pat-Ack (mentioned above). While PoxB decarboxylates pyruvate to acetate aerobically, the Pat-Ack complex is active under both aerobic and anaerobic conditions, converting acetyl-CoA to acetate (Hahm et al., 1994; Yang et al., 1999). The Pat-Ack reactions are sequential, reversible, and considered important for balancing the cellular carbon flux during exponential, aerobic and anaerobic growth (Chang et al., 1999; Avison et al., 2001). Pat converts acetyl-CoA and inorganic phosphate to acetyl phosphate (acetyl-P) and CoA, while Ack catalyzes the formation of ATP and acetate from acetyl-P and ADP (Rose et al., 1954). In E. coli, the pat and ack genes are organized in an operon (Kakuda et al., 1994). Mutants defective for Pat can neither synthesize acetate nor grow anaerobically (Gupta and Clark, 1989).

Under conditions in which anaerobically maintained $E$. colicells are accumulating high levels of pyruvate or growing in a low $\mathrm{pH}$ medium, they can convert pyruvate to lactate through the activity of lactate dehydrogenase (Ldh; Clark, 1989; Figure 1). Alternatively, pyruvate or phosphoenolpyruvate (PEP) can be converted to a C4 intermediate of the TCA cycle by the catalytic addition of $\mathrm{CO}_{2}$ (Clark, 1989; Figure 1). In some cases, malic enzymes can carboxylate pyruvate forming malate, while phosphoenolpyruvate carboxylase $(\mathrm{Ppc})$ can catalyze the formation of oxaloacetate (OAA) from PEP and $\mathrm{CO}_{2}$ (Clark, 1989; Figure 1). Both OAA and malate are then further reduced to succinate (Clark, 1989; Figure 1). This conversion is catalyzed by the sequential action of malate dehydrogenase (Mdh), fumarase (FumB and FumC), and fumarate reductase (FrdABCD; Clark, 1989; Figure 1); the gene encoding fumarase $\mathrm{B}$ is induced under anaerobic conditions (Woods et al., 1988). Since the amount of NADH generated varies with the nature of the substrate and the composition of the fermentation products generated, the redox balance and recycling of the NADH can be achieved by modulating the activities of the various fermentation pathways, which would result in a mix of end products, including ethanol, formate, acetate, and lactate (when necessary). Hence, E. coli mutants of $l d h$ show no growth defects under anaerobic conditions because of compensatory pathways (Mat-Jan et al., 1989). Tarmy and Kaplan (1968) reported that fermentative Ldh is allosterically regulated and that its activity increases as the cellular pyruvate concentration increases; when pyruvate concentrations are low, the enzyme has very low activity. In contrast, E. coli adhE mutants do not synthesize alcohol dehydrogenase and cannot grow anaerobically on sorbitol, glucose, or gluconate since they cannot maintain redox balance, but they are able to ferment glucuronate (as reviewed by Clark, 1989).

\section{IN ALGAE (Figure 2)}

Fermentation of stored organic compounds by phototrophic microorganisms can represent a significant part of their overall 


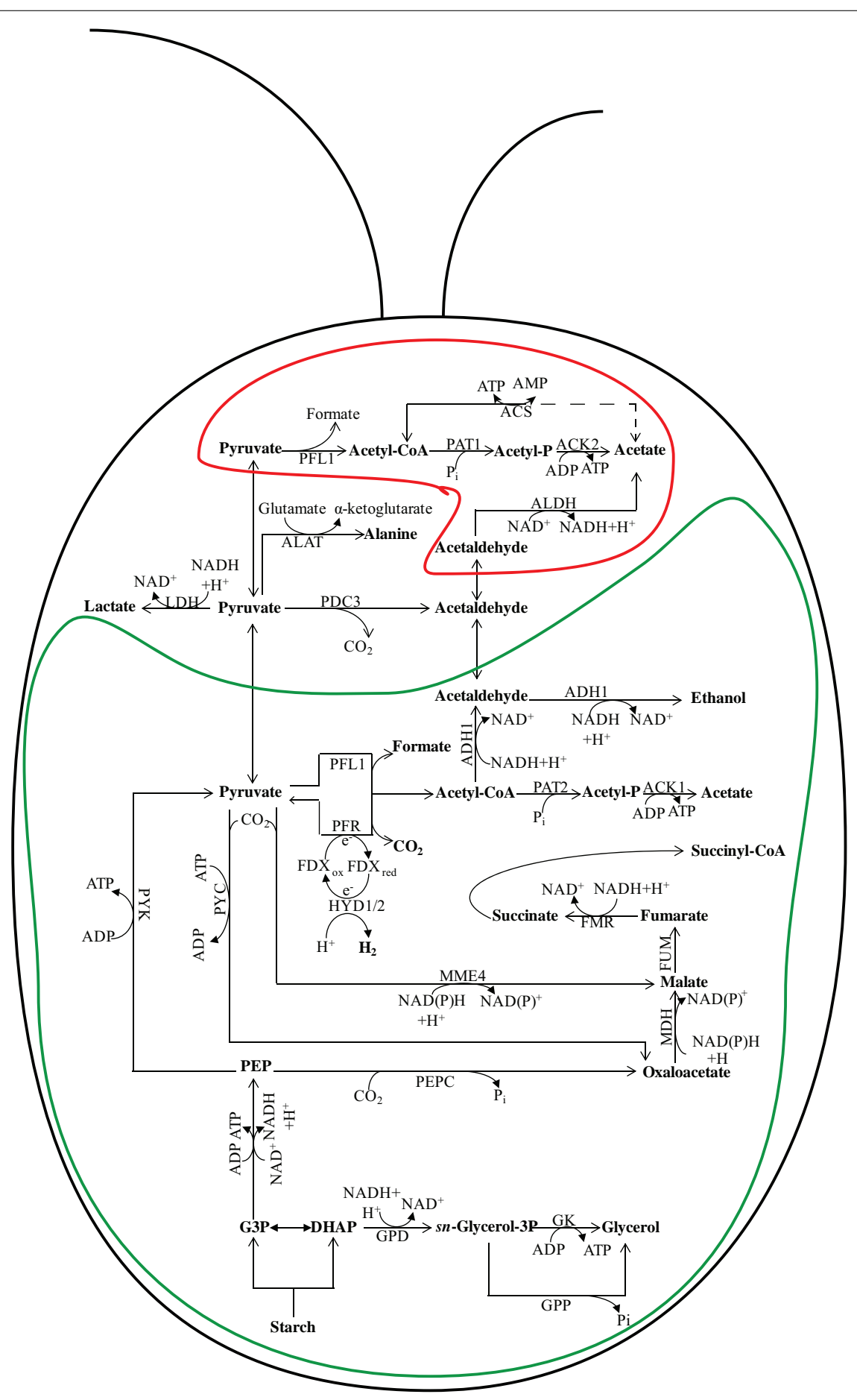

FIGURE 2 | Fermentation pathways in Chlamydomonas. In wild-type (WT) Chlamydomonas cells, the major fermentative products are formate, acetate, and ethanol, with $\mathrm{CO}_{2}$ and $\mathrm{H}_{2}$ generated as minor products. The pathway leading to fermentative succinate generation is not readily detected in WT cells grown under laboratory conditions, but becomes prominent in the hydEF-1 mutant (Dubini et al., 2009). An increase in lactate production, which is almost undetectable in fermenting WT cells, is observed in the pfl1 mutants (Philipps et al., 2011; Burgess et al., 2012; Catalanotti etal., 2012). Glycerol accumulation occurs in the adh 1 single and the pfl1-1adh1 double mutants (Catalanotti etal., 2012; Magneschi et al., 2012). The protein designations in this figure are: FMR for fumarate reductase; MME4 for malic enzyme 4; PDC3 for pyruvate decarboxylase 3; PEPC for phosphoenolpyruvate carboxylase; PYC for pyruvate carboxylase; PYK for pyruvate kinase; PFR for pyruvate ferredoxin oxidoreductase; ACS for acetyl-CoA synthase; FDX for ferredoxin; HYDA1 and HYDA2 for the hydrogenases; GK for glycerol kinase; GPD for sn-glycerol-3 phosphate dehydrogenase and GPP for glycerol 3-phosphate phosphatase. See Figure 1 for ACK1; ACK2; ADH1; ALDH; FUM; LDH; MDH; PAT1; and PAT2 designations. The enclosure delineated by a green line represents the chloroplast while the enclosure delineated by a red line represents the mitochondrion. The placement of some of the enzymes into specific subcellular compartments is speculative. 
energy budget as many of these ecologically important organisms spend much of their lifecycle under light-limited, hypoxic/anoxic conditions. Several species of water-oxidizing, photosynthetic algae can metabolize endogenous polysaccharides or secondary metabolites when the environment becomes anoxic, enabling them to generate the ATP necessary to drive metabolic and energyrequiring processes (Gfeller and Gibbs, 1984, 1985; Kreuzberg, 1984; Gibbs et al., 1986; Ohta et al., 1987). During dark fermentation, cellular polysaccharide reserves are catabolized, generating the needed ATP, while the co-produced NADH must be reoxidized. The primary fermentation pathways used during anoxia vary among different algal species (Ohta et al., 1987; Atteia et al., 2013). Green algae such as Chlamydomonas reinhardtii, Chlamydomonas moewusii, Chlorogonium elongatum, and Chlorella fusca ferment starch to a variety of end products including acetate, ethanol, formate, glycerol, lactate, $\mathrm{H}_{2}$, and $\mathrm{CO}_{2}$ (Gaffron and Rubin, 1942; Ben-Amotz, 1975; Klein and Betz, 1978; Grossman et al., 2007; Mus et al., 2007). The heterofermentation patterns vary among green algal species (and sometimes among strains) and can also significantly vary with changes in environmental conditions, including the medium composition and carbon source. For Chlamydomonas, dark fermentation leads to the production of formate, acetate, and ethanol in a 2:1:1 ratio (Mus et al., 2007; Figure 2). In contrast, Chlamydomonas moewusii cells do not excrete formate during exposure to dark anoxic conditions; the major end products synthesized by this organism are acetate, glycerol, and ethanol (Klein and Betz, 1978; Meuser et al., 2009).

Some algae do not excrete fermentation products, but instead store them (reviewed by Müller et al., 2012; Atteia et al., 2013). Euglena gracilis synthesizes ATP when maintained under anoxic conditions with the concomitant accumulation of up to $60 \%$ fatty acids by dry weight (Inui et al., 1982). When the cells are returned to oxic conditions, the stored fatty acids can be converted back to acetyl-CoA, which can then be oxidized to $\mathrm{CO}_{2}$ or used to form paramylon reserves (Inui et al., 1982).

Diatoms and dinoflagellates are present in anoxic marine sediments (Jewson etal., 2006). The diatoms that inhabit these sediments accumulate high concentrations of nitrate (Lomstein et al., 1990), which is used as an electron acceptor in respiratory metabolism (e.g., generating ammonium) allowing these organisms to survive under dark anoxic condition (Kamp et al., 2011).

\section{Enzymes of fermentation in Chlamydomonas (Figure 2)}

Currently, most information on fermentation metabolism in algae comes from studies of Chlamydomonas (Gfeller and Gibbs, 1984, 1985; Kreuzberg, 1984; Gibbs et al., 1986; Ohta et al., 1987; Hemschemeier and Happe, 2005; Grossman et al., 2007, 2011; Mus et al., 2007; Hemschemeier et al., 2008; Dubini et al., 2009; Philipps et al., 2011; Burgess et al., 2012; Catalanotti et al., 2012; Magneschi et al., 2012). Genes encoding proteins associated with a diverse set of fermentative pathways have been identified on the Chlamydomonas genome, while a number of biochemical studies have revealed various fermentation circuits. The flexibility among the different pathways for catabolism of stored carbon under dark, anoxic conditions has been demonstrated through analyses of various mutants perturbed for these pathways (Mus et al., 2007; Dubini et al., 2009; Philipps et al., 2011; Burgess et al., 2012; Catalanotti et al., 2012; Magneschi et al., 2012). This flexibility allows Chlamydomonas to satisfy its energy requirements as $\mathrm{O}_{2}$ from the surrounding environment is depleted.

Over the course of the day there is a natural cycle for storage and utilization of fixed carbon. In phototrophic organisms, polysaccharides (sometimes lipids) accumulate in cells during daylight hours when photosynthetic $\mathrm{CO}_{2}$ fixation is a dominant metabolic process. During the evening, much of the starch reserve can be hydrolyzed to sugars by amylase activity (Ball, 1998; Dauvillee et al., 2001a,b; Zabawinski et al., 2001) and then, through the activity of glycolysis, be converted to pyruvate (Figure 2). As in bacteria, pyruvate fuels fermentation processes, serving as substrate for pathways that generate various organic acids, acetyl-CoA, alcohols, $\mathrm{CO}_{2}$, and $\mathrm{H}_{2}$. Chlamydomonas has multiple pathways for converting pyruvate to acetyl-CoA (Hemschemeier and Happe, 2005; Atteia et al., 2006; Grossman et al., 2007; see Figure 2 for details). Three enzymes involved in these pathways are pyruvate formate lyase (PFL1), pyruvate ferredoxin oxidoreductase (PFR, often referred to as PFOR), and the pyruvate dehydrogenase $(\mathrm{PDH})$ complex. As $\mathrm{PDH}$ generates $\mathrm{NADH}$, a product that must be re-oxidized to sustain fermentation metabolism, it is presumed that PFL1 and PFR are the favored pathways for pyruvate catabolism in hypoxic/anoxic cells (Figure 2). While PFL1 catalyzes the conversion of pyruvate to acetyl-CoA and formate, in the PFR reaction pyruvate is oxidized to acetyl-CoA and $\mathrm{CO}_{2}$ with the concomitant generation of reduced ferredoxin (FDX). FDX can then pass reducing equivalents to hydrogenases to generate $\mathrm{H}_{2}$ (Happe and Naber, 1993; Ghirardi et al., 1997, 2000, 2007; Melis et al., 2000; Melis and Happe, 2001; Müller, 2003). However, the reduced FDX can also serve as a substrate for nitrite and sulfate/sulfite reductases (Ghirardi et al., 2008).

The acetyl-CoA produced by PFL1 and PFR reactions is either reduced to ethanol by alcohol/aldehyde dehydrogenase 1 (ADH1; Hemschemeier and Happe, 2005; Atteia et al., 2006; Dubini et al., 2009), or metabolized to acetate by the PAT-ACK (Atteia et al., 2006). An alternative pathway for ethanol production may be direct decarboxylation of pyruvate to $\mathrm{CO}_{2}$ and acetaldehyde through the activity of pyruvate decarboxylase (PDC3). The acetaldehyde generated in this reaction can be reduced to ethanol by $\mathrm{ADH}$ (either the same enzyme that catalyzes acetyl-CoA reduction or a distinct enzyme, e.g., $\mathrm{ADH} 2$ ). While the conversion of acetyl-CoA to ethanol by ADH1 oxidizes two NADH molecules, only a single $\mathrm{NADH}$ is oxidized in the PDC pathway.

Mutants in specific branches of fermentative metabolism have proven extremely valuable for elucidating the various routes of fermentation metabolism in Chlamydomonas, which are shown in Figure 2.

\section{Formate production}

Formate was demonstrated to be the dominant, secreted organic acid synthesized by Chlamydomonas maintained in anoxic conditions at near neutral pH in dark (Kreuzberg, 1984; Gibbs et al., 1986). The synthesis of formate by PFL1 uses a free-radical mechanism to catalyze the homolytic cleavage of pyruvate into 
formate and acetyl-CoA. This reaction depends upon a radical $S$-adenosyl methionine-dependent activating enzyme, designated PFL-AE (Atteia et al., 2006; Hemschemeier et al., 2008), which is usually present as an inactive form in aerobic cells, and is allosterically activated by pyruvate. In Chlamydomonas, PFL1 appears to be located in both mitochondria and chloroplasts (Kreuzberg et al., 1987; Atteia et al., 2006).

Algal strains deficient for PFL1 activity were isolated by independent groups (Philipps et al., 2011; Catalanotti et al., 2012) using different strategies (Burgess et al., 2012). The elimination of PFL1 activity in Chlamydomonas led to a marked accumulation of extracellular lactate, elevated pyruvate decarboxylation, and extracellular ethanol accumulation (Figure 2). The accumulation of lactate in the medium of pfl1 mutants allows for recycling of $\mathrm{NADH}$ as a consequence of pyruvate reduction by LDH. Catalanotti et al. (2012) also demonstrated that the pfl1 mutant accumulates elevated intracellular levels of lactate and alanine. Additionally increased intracellular levels of succinate, malate, and fumarate were observed, suggesting operation of the left branch of the reverse TCA reactions to recycle NADH.

\section{Ethanol production}

Acetyl-CoA produced by PFR/PFL1 activities can be metabolized to generate ATP by conversion to acetate or to help maintain redox balance by conversion to ethanol (Mus et al., 2007). Chlamydomonas possesses three distinct enzymes potentially important for ethanol production when the cells become anoxic: ADH1 (putative dual-function alcohol/acetaldehyde dehydrogenase; Mus et al., 2007; Hemschemeier et al., 2008; Magneschi et al., 2012), and two other putative alcohol dehydrogenases that were identified based on protein homology, designated ADH2 (Augustus version 5.0 protein identifier 516421) and ADH3 (Augustus version 5.0 protein identifier 516422 ). ADH1 has been localized to chloroplasts (Terashima et al., 2010).

A Chlamydomonas mutant devoid of ADH1 was unable to synthesis either ethanol or $\mathrm{CO}_{2}$ when the cells were transferred to anoxic conditions (Magneschi etal., 2012). The inability of the adh1 mutant to accumulate ethanol and $\mathrm{CO}_{2}$, while synthesizing low levels of formate, suggests that the acetaldehyde synthesized by PDC3 and the acetyl-CoA synthesized by PFL1 and PFR cannot be rapidly reduced in the mutant. These findings also indicate that $\mathrm{ADH} 1$ is the only acetaldehyde-alcohol dehydrogenase in Chlamydomonas capable of reducing acetyl-CoA or acetaldehyde to ethanol under the conditions used in this study. Interestingly, the adh1 strain was able to compensate for its inability to reduce acetyl-CoA or acetaldehyde to ethanol by reducing a significant amount of pyruvate to lactate. This elevated lactate accumulation was not as high as the level measured in pfll (Philipps et al., 2011; Burgess et al., 2012; Catalanotti et al., 2012). However, the adh1 mutants also accumulated high extracellular and intracellular levels of glycerol relative to anoxic wild-type (WT) cells. This acclimation response removes a significant amount of the C3 metabolites at the dihydroxyacetone phosphate (DHAP) step of the glycolytic pathway, which is prior to the reduction of $\mathrm{NAD}^{+}$ to NADH; the DHAP is then used as a substrate to re-oxidize $\mathrm{NADH}$ in the synthesis of glycerol (Figure 2).

\section{Acetate production}

The acetyl-CoA that is produced by PFL1 or PFR activities can be converted to acetate by PAT and ACK (Mus etal., 2007). Two parallel pathways have been identified in Chlamydomonas; PAT1-ACK2 appear to be mitochondrial while PAT2-ACK1 are in the chloroplast (Atteia etal., 2006, 2009; Terashima et al., 2011; Figure 2). Interestingly, the PAT2 and ACK1 genes are contiguous on the genome while PAT1 and ACK2 are far apart on the same chromosome (http://genome.jgi-psf.org/Chlre4/ Chlre4.home.html).

While PAT-ACK activities comprise the predominant pathways for acetate formation under dark anaerobiosis, other enzymes are present on the Chlamydomonas genome that may play a role in acetate synthesis. Four genes encoding homologs of acetyl-CoA synthase (ACS) and eight genes encoding homologs of aldehyde dehydrogenase (ALDH) have been identified on the Chlamydomonas genome (Kirch et al., 2004, 2005; Brocker et al., 2012). The ACSs catalyze the putatively reversible conversion of acetate to acetyl-CoA (dash line in Figure 2). The ALDH reaction produces $\mathrm{NAD}(\mathrm{P}) \mathrm{H}$ during the conversion of acetaldehyde to acetate, therefore it is unlikely that these enzymes are active in fermentative metabolism when the cells require regeneration of reducing power (Kirch et al., 2004, 2005; Brocker et al., 2012). To date, there is no biochemical evidence to demonstrate that these alternative pathways for acetate generation are active in Chlamydomonas. In bacteria, the two pathways active under aerobic conditions that generate acetate are the Pat-Ack pathway, which is active in exponentially growing cells, and the PoxB pathway, which dominates during late exponential and stationary phase (Dittrich et al., 2005). It is uncertain whether or not similar regulatory features occur in Chlamydomonas.

The presence and/or production of acetate as Chlamydomonas cells become anoxic was found to be critical for maintenance of anoxic conditions in the light since acetate assimilation promotes $\mathrm{O}_{2}$ utilization (Kosourov et al., 2007; Morsy, 2011). The level of acetate accumulation during fermentative metabolism has proven to be difficult to predict, probably because it can also be used for the biosynthesis of key metabolites in anoxic cells, provided sufficient ATP and NAD $(\mathrm{P}) \mathrm{H}$ is available. The $a d h 1$ mutant exhibits a higher ratio of acetate production under anoxic conditions compared to WT cells, which reflects the elimination of ethanol production from the acetyl-CoA that is generated by PFL1 and PFR activities in the mutant strain; glycerol and lactate production serve as the primary NADH re-oxidation mechanisms in this mutant (Magneschi et al., 2012). In contrast, the pfl1 mutant strains exhibit strongly reduced acetate accumulation (Burgess et al., 2012; Catalanotti etal., 2012); this decrease is likely due to a diminished intracellular acetyl-CoA pool.

\section{$\mathrm{H}_{2}$ production}

The mitochondria of cells maintained in aerobic conditions use $\mathrm{PDH}$ to convert pyruvate to acetyl-CoA; the acetyl-CoA generated can be metabolized to $\mathrm{CO}_{2}$ by the TCA cycle. In some animals $\mathrm{PDH}$ can function under anaerobic conditions (reviewed by Tielens and van Hellemond, 1998; Tielens et al., 2002; Hoffmeister et al., 2005; Tucci et al., 2010; Atteia et al., 2013). However, in many prokaryotes and eukaryotes, pyruvate oxidation in the absence of 
$\mathrm{O}_{2}$ is typically mediated by PFR. PFR belongs to a large family of thiamine pyrophosphate (TPP)-dependent enzymes. It catalyzes the oxidative cleavage of the carbon-carbon bond of the carboxyl group of pyruvate to liberate $\mathrm{CO}_{2}$ and reducing equivalents, with the attachment of the resulting acetyl group to CoA. However, unlike $\mathrm{PDH}, \mathrm{PFR}$ can also function in the reverse direction catalyzing the production of pyruvate from $\mathrm{CO}_{2}$ and acetyl-CoA (Evans et al., 1966; see below), with FDX or flavodoxin serving as electron donors (Charon et al., 1999; Ragsdale, 2003; Figure 2). In Chlamydomonas, the reduced FDX generated from pyruvate oxidation by PFR activity can be re-oxidized by hydrogenases, generating $\mathrm{H}_{2}$ (Müller, 2003), or by reactions that enzymatically reduce nitrite and sulfate/sulfite. Hydrogenases are widespread among prokaryotes, whereas they are not as common among eukaryotes, and are restricted to a subset of unicellular eukaryotes, including photosynthetic algae (Meuser et al., 2011; Müller et al., 2012). Chlamydomonas hydrogenases belong to the class of [FeFe]-hydrogenases in which a $[4 \mathrm{Fe} 4 \mathrm{~S}]$ cluster is linked through a cysteine residue to a 2Fe- cluster (Peters et al., 1998; Mulder et al., 2011).

Hydrogen production in algae is likely to have significant impacts on redox poising, photoprotection, and fermentative energy metabolism. Hydrogen production is coupled to cellular metabolism in a variety of ways, all of which are associated with $\mathrm{O}_{2}$ limitation: (i) direct biophotolysis, (ii) indirect biophotolysis, and (iii) dark fermentative metabolism (Figure 3). Direct biophotolysis involves light-dependent oxidation of water by photosystem II (PSII), the transfer of electrons from PSII to photosystem I (PSI), light-dependent excitation of PSI with the concomitant reduction of FDX and the subsequent transfer of electrons from FDX to hydrogenase (Benemann et al., 1973; Greenbaum, 1982; Happe and Naber, 1993; Miura, 1995; Ghirardi et al., 2007). During direct biophotolysis, the $\mathrm{O}_{2}$ generated by PSII must be reduced in order to prevent the accumulation of $\mathrm{O}_{2}$ to levels that would inhibit the hydrogenase. Indirect biophotolysis involves non-photochemical reduction of the PQ pool by $\mathrm{NAD}(\mathrm{P}) \mathrm{H}$ generated as a consequence of catabolic metabolism, followed by light-dependent FDX reduction by PSI and the subsequent transfer of electrons from FDX to hydrogenase (Cournac et al., 2000; Kosourov et al., 2003; Mus et al., 2005; Chochois et al., 2009). In the third $\mathrm{H}_{2}$-production pathway, starch catabolism provides electrons to the hydrogenases under dark fermentative conditions (Gfeller and Gibbs, 1984; Kreuzberg, 1984; Ohta et al., 1987; Happe etal., 1994; Ghirardi et al., 1997; Melis and Happe, 2001; Posewitz etal., 2004; Mus et al., 2007; Dubini et al., 2009).

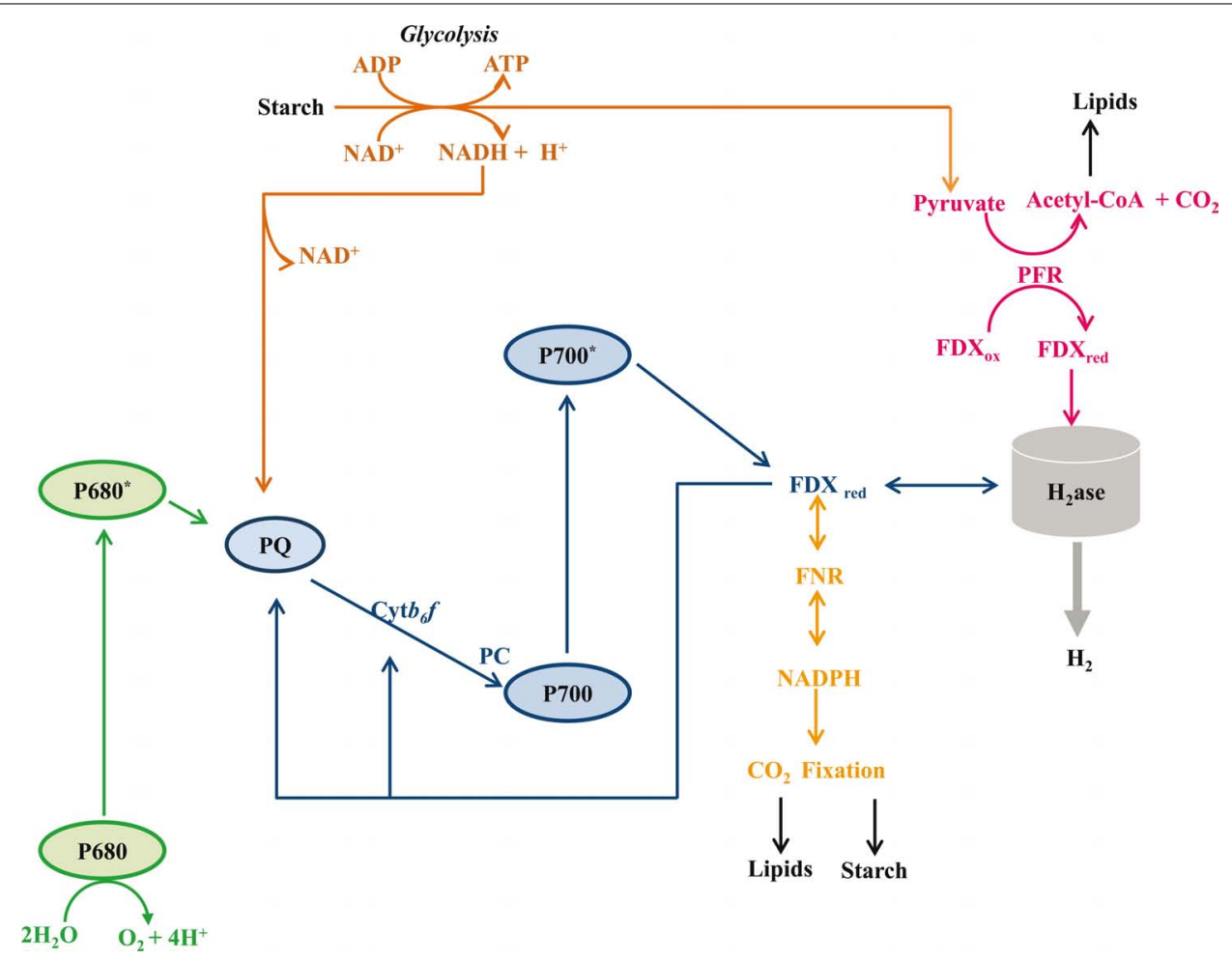

FIGURE 3 | Metabolic pathways associated with hydrogenase activity. Five distinct metabolisms are depicted: (1) $\mathrm{H}_{2}$ production dependent on the complete photosynthetic electron transport system (PSII, PSI, FDX, $\mathrm{H}_{2}$ ase; green and blue lines); (2) $\mathrm{H}_{2}$ production requiring starch catabolism and PSI activity (starch, glycolysis, PQ, PSI, FDX, $\mathrm{H}_{2}$ ase; brown and blue lines); (3) $\mathrm{H}_{2}$ production in the dark from pyruvate oxidation (starch, glycolysis, pyruvate, FDX, $\mathrm{H}_{2}$ ase; brown and magenta lines); (4) $\mathrm{H}_{2}$ oxidation coupled to $\mathrm{CO}_{2}$ reduction, with respiratory $\mathrm{O}_{2}$ uptake used to generate $\operatorname{ATP}\left(\mathrm{H}_{2}, \mathrm{H}_{2}\right.$ ase, FDX, FNR, $\mathrm{NAD}(\mathrm{P}) \mathrm{H}, \mathrm{CO}_{2}$ fixation; orange line);
(5) $\mathrm{H}_{2}$ oxidation coupled to PSI-driven cyclic electron flow and ATP production $\left(\mathrm{H}_{2}, \mathrm{H}_{2}\right.$ ase, FDX, PSI, FDX and continued cycling; blue line). Abbreviations are: $\mathrm{Cytb}_{6} f$, cytochrome $b_{6} f$ complex; FDX, ferredoxin; FNR, ferredoxin $\mathrm{NAD}(\mathrm{P})^{+}$reductase; $\mathrm{H}_{2}$ ase hydrogenase enzyme; PC, plastocyanin; PFR, pyruvate ferredoxin oxidoreductase; $P Q$, plastoquinone pool; P700, reaction center of photosystem I; P680, reaction center of photosystem II. For simplicity we have not tried to scale the energy potential of the electron carriers downstream of FDX. 
Hydrogenases also function in $\mathrm{H}_{2}$ uptake, with two distinct uptake pathways described in Chlamydomonas (Gaffron, 1944; Kessler, 1974; Maione and Gibbs, 1986a,b; Chen and Gibbs, 1992a; Figure 3). In the first pathway, $\mathrm{H}_{2}$ oxidation and cyclic PSI activity in the light are linked to RuBisCO-mediated anaerobic $\mathrm{CO}_{2}$ fixation. Electrons from $\mathrm{H}_{2}$ are used to reduce FDX, which then reduces $\mathrm{FDX}-\mathrm{NAD}(\mathrm{P})$ oxidoreductase (FNR), leading to the generation of $\mathrm{NAD}(\mathrm{P}) \mathrm{H}$ which, along with the ATP generated by cyclic electron flow, can be used to fix $\mathrm{CO}_{2}$. This pathway requires the absence of $\mathrm{O}_{2}$ evolution from PSII. In the second pathway, termed the oxyhydrogen reaction, $\mathrm{H}_{2}$ oxidation occurs concomitantly with the uptake of low levels of $\mathrm{O}_{2}$ in a process that can be coupled to $\mathrm{CO}_{2}$ fixation (Gaffron and Rubin, 1942; Gaffron, 1944; Russell and Gibbs, 1968; Kessler, 1974; Chen and Gibbs, 1992a). Although not well characterized, it is posited that $\mathrm{H}_{2}$ oxidation provides the reducing equivalents for $\mathrm{CO}_{2}$ fixation and that the low levels of $\mathrm{O}_{2}$ present are respired to provide ATP (Gaffron and Rubin, 1942; Gaffron, 1944; Maione and Gibbs, 1986a; Chen and Gibbs, 1992a).

Recently, mutants were obtained in each of the two HYDA genes of Chlamydomonas, HYDA1 and HYDA2 (Meuser et al., 2012). The phenotypes of the single (hydA1 and hydA2) and double (hydA1-hydA2 ) mutants were analyzed under both light and dark anoxic conditions. Both single mutants could catalyze $\mathrm{H}_{2}$ production from reductant generated from either fermentative or photosynthetic metabolism. However, the contribution of the HYDA2 enzyme to $\mathrm{H}_{2}$ photoproduction under the conditions tested was approximately $25 \%$ of that of HYDA1 (Godman et al., 2010; Meuser et al., 2012).

The impact of the hydEF-1 lesion on fermentation is more interesting since it demonstrates the flexibility of Chlamydomonas anaerobic metabolism (see below). This mutant is unable to assemble the inorganic constituents of the hydrogenase active site, and consequently cannot catalyze $\mathrm{H}_{2}$ synthesis (Posewitz et al., 2004).

\section{Succinate production}

Anoxic cultures of the Chlamydomonas hydEF-1 mutant exhibit lower $\mathrm{CO}_{2}$ evolution and reduced extracellular formate, acetate, and ethanol accumulation. Interestingly, the mutant synthesizes elevated levels of extracellular succinate (Dubini et al., 2009; Figure 2), indicating activation of a fermentative pathway that is not operating at significant levels in WT cells. Microarray data and metabolite analyses suggest that carboxylation of pyruvate in the hydEF-1 mutant leads to the synthesis of either malate or OAA (or both), which is subsequently converted to succinate via reverse reactions of the TCA cycle. Activation of the reductive TCA branch as a means of recycling NADH was previously observed in anaerobic bacteria (Gray and Gest, 1965; Schauder et al., 1987; Buchanan and Arnon, 1990; Beh et al., 1993; Yoon et al., 1999), in the green alga Selenastrum minutum (Vanlerberghe et al., 1989, 1990) and in vascular plants (Sweetlove et al., 2010), but was not known to occur in Chlamydomonas.

The alternative pathway suggested by Dubini et al. (2009) not only explains succinate accumulation under anaerobic conditions, but also raises the possibility that Chlamydomonas could potentially operate a complete reverse TCA cycle. This would require that PFR functions in the direction of pyruvate synthesis under the appropriate metabolic conditions. Various researchers have suggested that PFR could function in the synthesis of pyruvate in Chlamydomonas (Chen and Gibbs, 1992b; Melis et al., 2007; Terashima et al., 2011; Figure 2). Chen and Gibbs (1992b) detected ATP-citrate lyase, as well as PFR and $\alpha$-ketoglutarate synthase activities in Chlamydomonas cell extracts, speculating that the existence of these three key enzyme activities indicated that the reverse TCA cycle could operate in Chlamydomonas. These authors showed that a Chlamydomonas mutant with a compromised Calvin-Benson cycle takes up $\mathrm{CO}_{2}$ in the dark under minimal aerobic conditions $\left(1 \% \mathrm{O}_{2}\right)$, and that the $\mathrm{CO}_{2}$ uptake is coupled to $\mathrm{H}_{2}$ oxidation (Chen and Gibbs, 1992a), suggesting that the reverse TCA cycle could be a significant pathway for $\mathrm{CO}_{2}$ assimilation when the Calvin-Benson cycle is compromised (Chen and Gibbs, 1992b). Hence, under these conditions $\mathrm{H}_{2}$ oxidation would provide the reducing equivalents to drive the reverse TCA cycle and to allow PFR to synthesize pyruvate, leading to the accumulation of an array of biosynthetic precursors. The possibility of PFR-dependent synthesis of pyruvate has also been observed in many hydrogenosome-containing eukaryotic organisms experiencing anaerobic conditions (Lindmark and Müller, 1973). Furthermore, in the unicellular microaerophilic eukaryote Trichomonas vaginalis, MME and PFR are central to carbohydrate metabolism in the hydrogenosomes (Müller, 1993). In addition, PFR and MME activities have been linked to malate production in the hyperthermophilic archaeon Thermococcus kodakaraensis KOD1, also suggesting reductive carboxylic acid cycle activity (Fukuda etal., 2005). The association of PFR and MME with pyruvate metabolism in hydrogenosome-containing anaerobic eukaryotes, the findings that a similar set of anoxic-induced proteins are associated with Chlamydomonas chloroplasts, and the metabolite data obtained with various Chlamydomonas strains exposed to anoxic, reductant-rich conditions, all suggest that the TCA cycle may operate in the reverse direction in Chlamydomonas chloroplasts in anoxic cells that have sufficient reducing equivalents and ATP.

\section{Lactate and glycerol production}

Glycerol and lactate are usually minor end products of green algal fermentation (Gfeller and Gibbs, 1984; Kreuzberg, 1984). Glycerol is synthesized from DHAP, and its synthesis results in recycling of one $\mathrm{NADH}$. The reaction precedes the formation of pyruvate and the $\mathrm{C} 3$ oxidation (NADH formation) step in glycolysis. Hence, glycerol and lactate production in the adhl mutant would allow for efficient recycling of $\mathrm{NADH}$, maintenance of redox balance and sustained glycolytic production of ATP even though the cells are unable to reduce acetaldehyde or acetyl-CoA to ethanol (Magneschi et al., 2012; Figure 2). The pfl1ladh1 double mutant cannot synthesize either formate or ethanol (Catalanotti et al., 2012; Figure 2). This strain, like $p f l 1$, secretes significant levels of lactate, however, like the adh1 mutant, it also synthesizes and secretes high levels of glycerol and acetate. Hence, this mutant exhibits a complete rerouting of glycolytic carbon to lactate and glycerol, transforming Chlamydomonas cells from a formate/acetate/ethanol to a glycerol/lactate fermenter (Catalanotti et al., 2012; Figure 2). 


\section{IN OTHER EUKARYOTES}

Eukaryotes specialized to thrive under aerobic conditions generally possess simple cytosolic fermentation pathways that enable them to tolerate short-term anoxia; these pathways facilitate accumulation of end products such as lactate, ethanol, and glycerol (reviewed by Müller etal., 2012). Some eukaryotes, including many algae, experience frequent exposure to anoxic conditions, where they are unable to use $\mathrm{O}_{2}$ as a terminal electron acceptor. These organisms have evolved a modest set of energy-generating pathways, which are reviewed below.

\section{Ethanol, lactate, and glycerol fermentation (Figures 4 and 5)}

When $\mathrm{O}_{2}$ in the environment is depleted, plants can use PDC to convert pyruvate to acetaldehyde, which is metabolized to ethanol by ADH (Gibbs and Greenway, 2003; Bailey-Serres and Voesenek, 2008). The ethanol generated in plant roots can rapidly diffuse into the rhizosphere, which limits its toxicity. Plants can also synthesize lactate under conditions of low $\mathrm{O}_{2}$. The transition from lactic to ethanolic fermentation appears to be controlled by the $\mathrm{pH}$ of the cytoplasm of the cell. A $\sim 0.6$ unit decrease in cytosolic $\mathrm{pH}$ favors PDC activity, which promotes ethanol production and limits lactate synthesis (reviewed by Bailey-Serres and Voesenek, 2008). This lactic to ethanolic switch is critical for maintaining cytosolic $\mathrm{pH}$ (Roberts et al., 1989). In addition to eliciting metabolic changes, low $\mathrm{O}_{2}$ can trigger alterations in plant morphology which include petiole or internode elongation, altered anatomy and cell ultrastructure in leaves and roots, development of lateral or adventitious roots and the formation of aerenchyma cells (Bailey-Serres et al., 2012).

Ethanol, lactate, and glycerol are common end products of fermentative metabolism in many organisms. The synthesis and excretion of ethanol allows carp to survive anaerobiosis for up to $\sim 5$ months (van Warde et al., 1993) and goldfish to withstand anoxia for several weeks (van den Thillart et al., 1983). It is notable

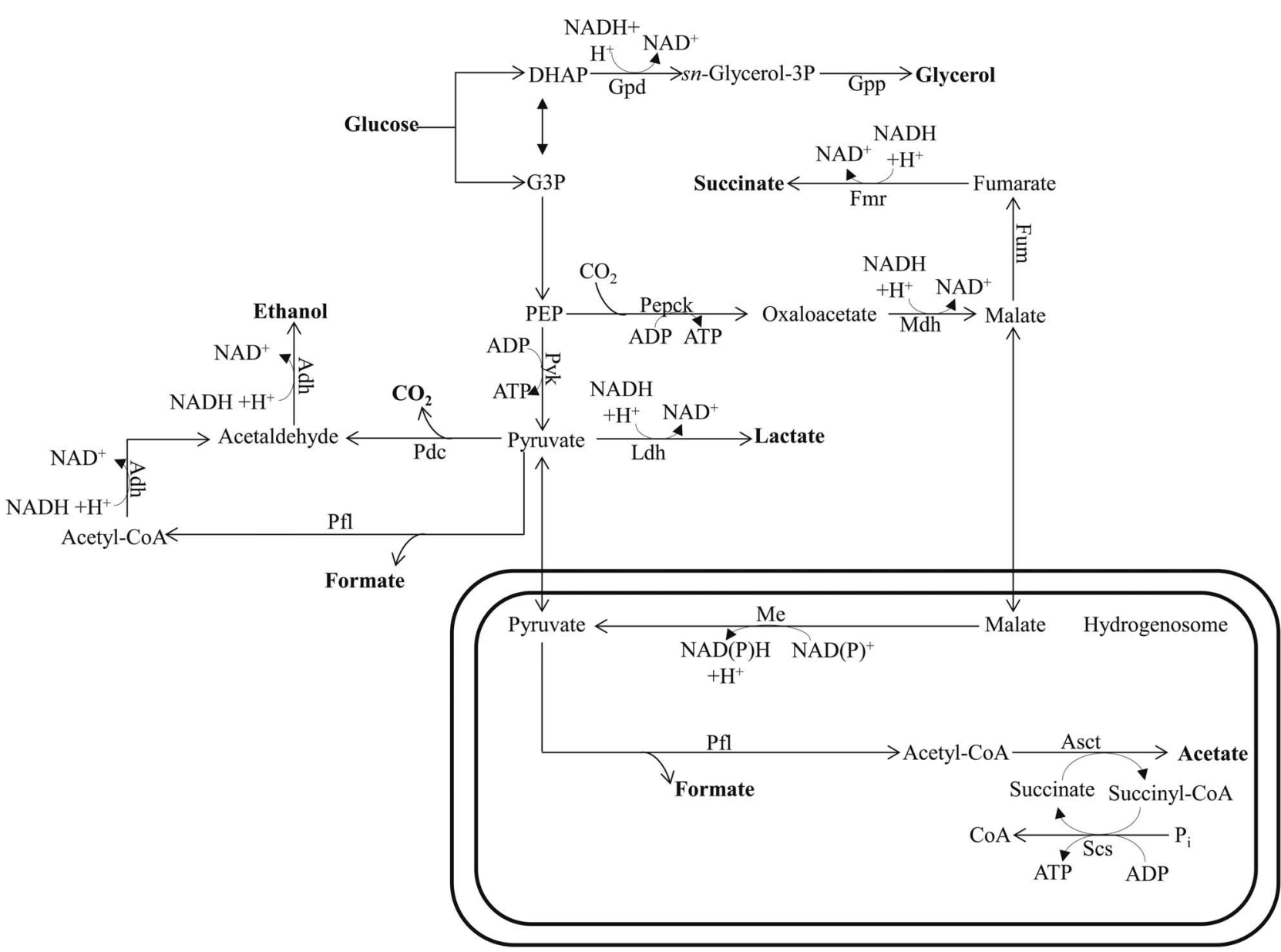

FIGURE 4 | Mixed-acid fermentative metabolism of the hydrogenosome-bearing anaerobic chytridiomycete fungus Piromyces. The circuitry is drawn based on data reported by Wang et al. (2001) and Boxma et al. (2004). This fungus uses pyruvate formate lyase for pyruvate catabolism in their hydrogenosomes. Glucose can also be metabolized in the cytosol to the end products succinate, lactate, formate, and ethanol. Bifunctional alcohol dehydrogenase (Adh), having both alcohol dehydrogenase and acetaldehyde dehydrogenase activities, mediates the cytosolic formation of ethanol. The protein designations in this figure are: Asct for acetate succinyl-CoA-transferase; Me for malic enzyme; Pepck for phosphoenolpyruvate carboxykinase; Scs for succinyl-CoA synthase; See Figure 1 for Adh; Fum; Ldh; Mdh; and Pfl designations and Figure 2 for Fmr; Gpd; Gpp; and Pdc designations. DHAP, dihydroxyacetone phosphate; G3P, glycerol-3-phosphate; PEP, phosphoenolpyruvate. 


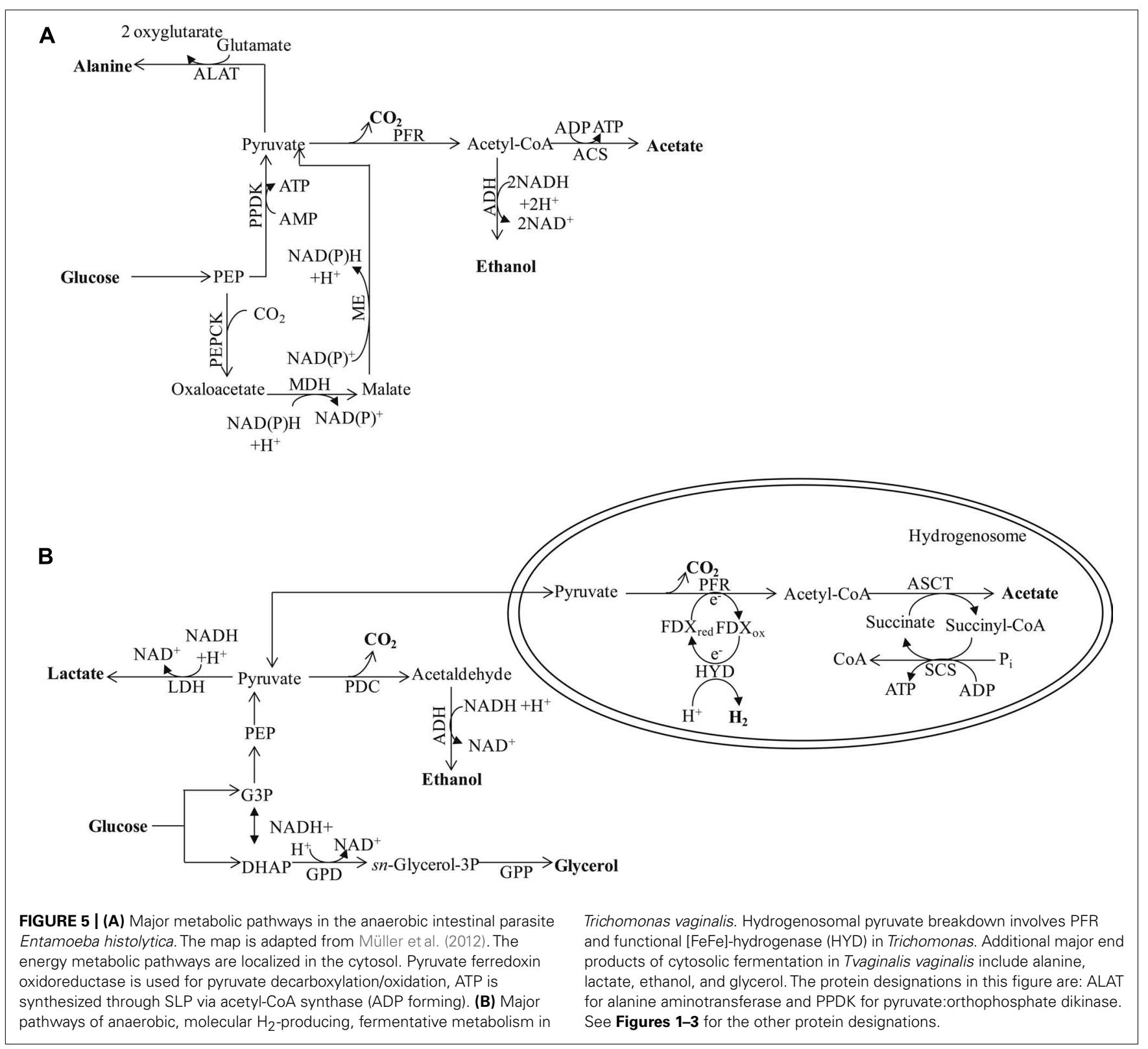

that the fermentation pathways used for these reactions appear to have their origins in a typical yeast-type PDC and ADH (van Warde et al., 1993; Figure 4). The fungi, a highly diverse group, can also ferment carbohydrates to lactate, glycerol, and ethanol. Glycerol acts as a redox valve under anaerobic conditions since it enables re-oxidation of NADH that is generated during the conversion of sugars into biomass. While fungi may also excrete organic acids, the levels are generally low; these acids include formate, acetate, lactate, and succinate (Figure 4). Formate production is not uncommon in fungi as a result of the activity of a cytosolic (and hydrogenosomal) PFL, which provides the acetyl-CoA for ethanol production (Boxma et al., 2004; Figure 4).

Finally, pathogenic amoebozoa such as Entamoeba histolytica often experience anaerobic conditions; their main end products of anaerobic energy metabolism are alanine, $\mathrm{CO}_{2}$, ethanol, and acetate (Müller et al., 2012). The enzymes responsible for generating these products are exclusively in the cytosol (Müller, 2003). The initial reactions of the pathway involve conversion of PEP to pyruvate by pyruvate orthophosphate dikinase (PPDK; Reeves, 1968; Figure 5A), which also generates ATP. The pyruvate is then oxidized via PFR to $\mathrm{CO}_{2}$ and acetyl-CoA, with the latter converted into a mixture of acetate and ethanol (Figure 5A). Alternatively the PEP can be carboxylated to OAA by PEP carboxytransferase, reduced to malate by malate dehydrogenase (MDH) and the malate then converted to pyruvate by the malic enzyme (ME; Figure 5A; as reviewed by Müller et al., 2012). Entamoeba possesses a bifunctional aldehyde/alcohol dehydrogenase (ADH), which represents a fusion protein that contains an $\mathrm{N}$-terminal aldehyde dehydrogenase domain and a C-terminal alcohol dehydrogenase domain. This enzyme regenerates $2 \mathrm{NAD}^{+}$, is present 
in many eukaryotes, and has been found to be highly expressed in Chlamydomonas (Mus et al., 2007; Catalanotti et al., 2012; Magneschi et al., 2012), other green algae and protozoan parasites such as Giardia intestinalis, Trichomonas, and euglenids.

Trichomonas vaginalis synthesizes ethanol from pyruvate in the cytosol via PDC and ADH. However, the main end products of T. vaginalis fermentative metabolism are distributed between the cytosol (glycerol, lactate, and ethanol) and the hydrogenosome $\left(\mathrm{CO}_{2}, \mathrm{H}_{2}\right.$, and acetate; Figure 5B). Similarly, Chlamydomonas can synthesize glycerol from DHAP, which is catalyzed by glycerol-3phosphate dehydrogenase and glycerol-3-phosphatase, and LDH can catalyze lactate accumulation. However, while both reactions in $T$. vaginalis occur in the cytosol, their locations in Chlamydomonas are not clear.

\section{Malate dismutation and acetate and propionate production (Figure 6)}

Fermentation in animals often involves malate dismutation. It is not uncommon for parasitic worms to switch to complete anaerobic metabolism once they are established in the host tissue. In parasitic mode they convert the PEP generated by glycolysis to OAA, which is then reduced to malate via a cytosolic malate dehydrogenase (Figure 6). This reaction results in re-oxidation of one molecule of NADH. The malate is then imported into the mitochondrion where dismutation occurs; a portion of the malate is oxidized to acetate (via pyruvate), and another is reduced to succinate. In the latter reaction, malate is converted to fumarate by FUM and the fumarate is reduced to succinate (Figure 6); this pathway is similar to the alternative fermentation pathway activated in the Chlamydomonas hydEF-1 mutant. Many organisms excrete succinate produced by malate dismutation rather than decarboxylating the succinate to generate propionate plus an extra molecule of ATP (Pietrzak and Saz, 1981; Müller et al., 2012; Figure 6). Interestingly, in the parasite system, fumarate reduction is performed by a membrane-associated, anaerobiosis-specific enzyme (FRD) that is coupled to an electron transport chain that functions specifically under anaerobic conditions. Electrons are transferred from NADH to fumarate via rhodoquinone (RQ; Figure 6) instead of ubiquinone (UQ, which is normally used under oxic conditions); the lower redox potential of RQ (relative to UQ) allows for the thermodynamically favorable use of electrons in the synthesis of succinate by FRD (as reviewed by Müller et al., 2012).

\section{Intracellular metabolite accumulation}

$\mathrm{O}_{2}$ deficiency is often associated with a wide range of excreted metabolites, but may also trigger more complicated responses involving sequestration of specific end products. Plants experiencing low $\mathrm{O}_{2}$ accumulate alanine and $\gamma$-aminobutyric acid (GABA; reviewed by Bailey-Serres and Voesenek, 2008). Upon re-oxygenation, alanine can be recycled back to pyruvate, and GABA can be converted to succinate. This set of amino acid oxidation reactions may minimize the decline in cytosolic $\mathrm{pH}$ and reduce the loss of fixed carbon as ethanol or lactate. Alanine also accumulates in T. vaginalis and in many animals belonging to the Excavata taxa (Edwards et al., 1989) as a minor end product.

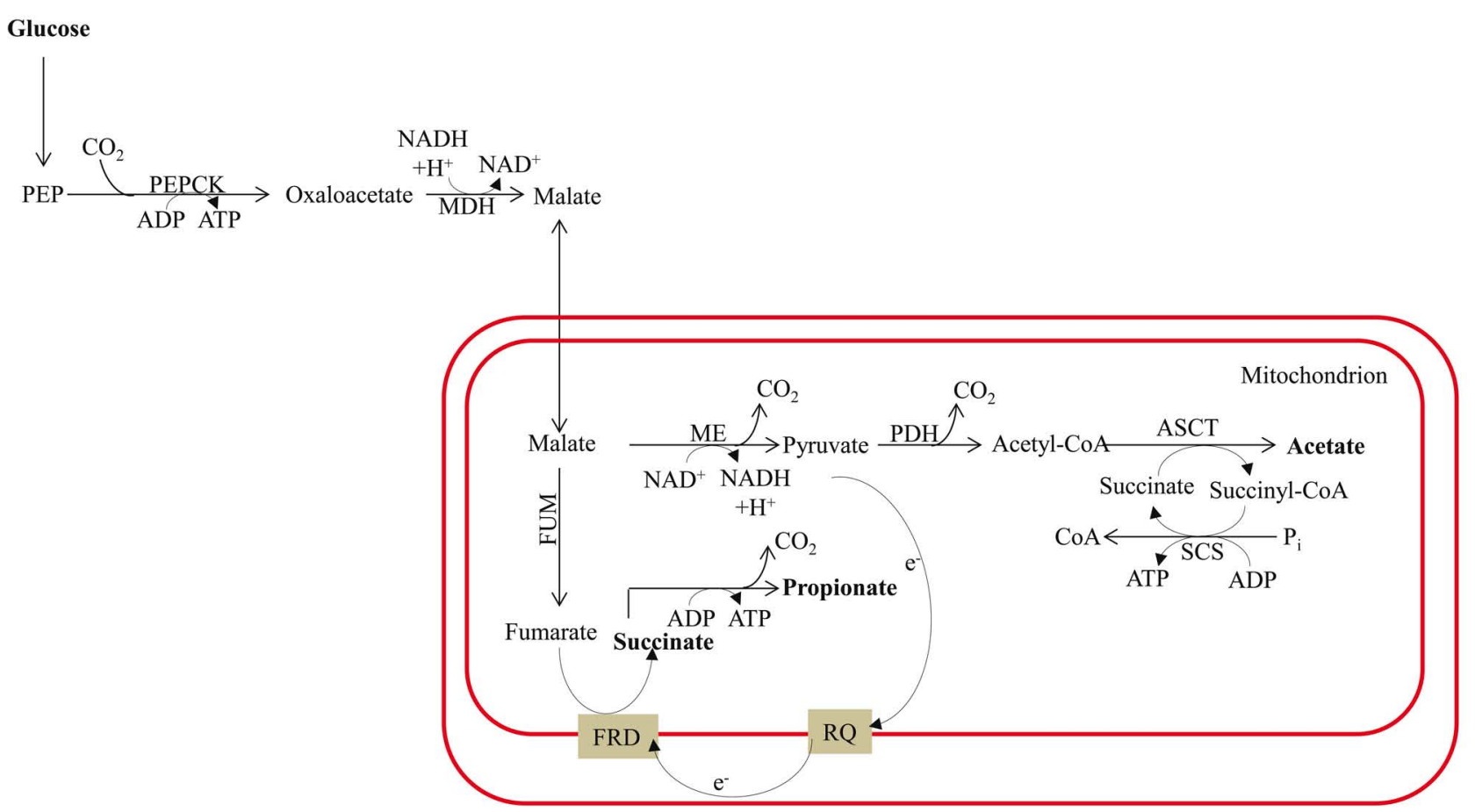

FIGURE 6 | Malate dismutation and energy metabolism in anaerobic mitochondria. The map is redrawn based on the review of Müller et al. (2012). The main end products are acetate and propionate, with minor amounts of succinate. The designations in this figure are: FRD for fumarate reductase; $\mathrm{PDH}$ for pyruvate dehydrogenase complex; and $\mathrm{RQ}$ for rhodoquinone. See previous figure for other designations. 
A less common fermentation process, but largely used in marine environments, involves opine formation. This pathway is localized to the cytosol and involves pyruvate condensation with an amino acid in a redox reaction that regenerates $\mathrm{NAD}^{+}$. A possible advantage of this alternative pathway for balancing cellular redox is that opine is less acidic than lactate. Moreover the process maintains an osmotic equilibrium since one amino acid is consumed per opine synthesized (Ballantyne, 2004).

\section{Denitrification (Figure 7)}

The capacity for nitrate respiration is widespread among bacteria, fungi, and other eukaryotic organisms (Morozkina and Kurakov, 2007). Details of the denitrification pathway have been studied in fungi and bacteria (see previous paragraphs). On the other hand, the enzymes required for nitrogen metabolism in foraminifera and diatoms are not well characterized, although the occurrence of the pathway was noted (Risgaard-Petersen et al., 2006; Kamp et al., 2011).

Numerous reports have demonstrated the presence of two main pathways for denitrification; one is localized in the mitochondrion and usually occurs under low $\mathrm{O}_{2}$ conditions, while the other, often referred to as ammonia fermentation, is localized in the cytosol (Zhou et al., 2001; Takasaki et al., 2004; Morozkina and
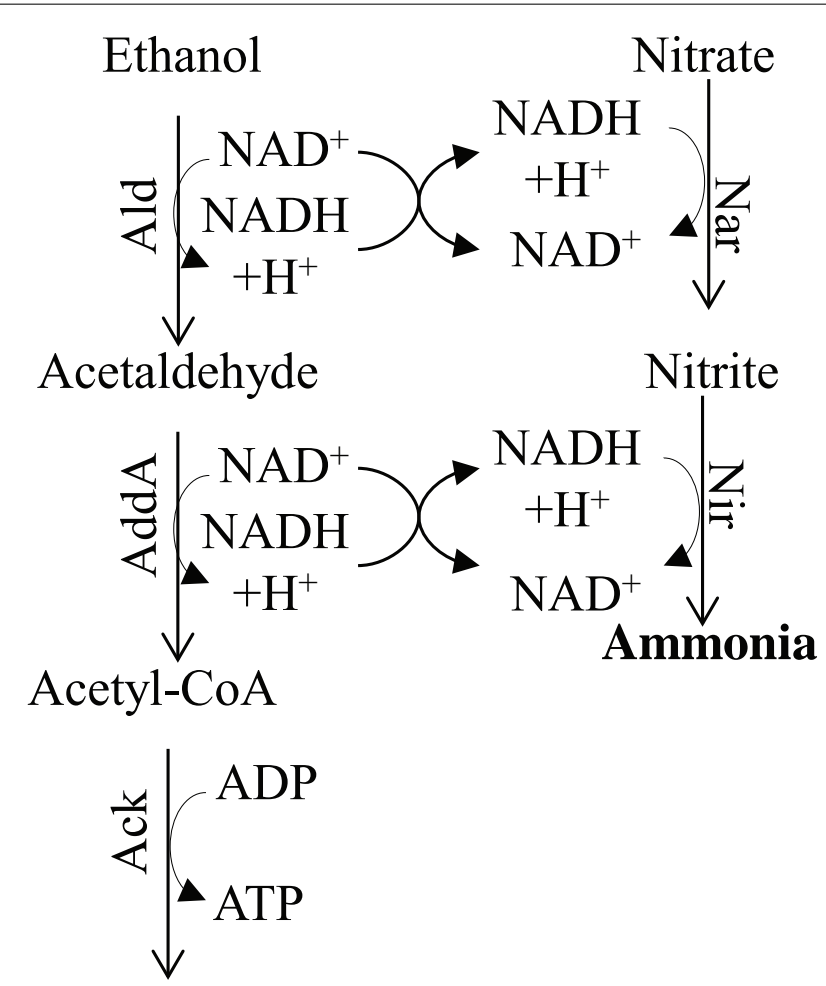

Acetate

FIGURE 7 | Metabolic pathway for ammonia fermentation coupled to acetogenic oxidation of ethanol and substrate-level phosphorylation. The protein designations in this figure are: Ald, alcohol dehydrogenase; Adda, acetaldehyde dehydrogenase; Nar, nitrate reductase; and Nir, nitrite reductase.
Kurakov, 2007; Figure 7). The latter pathway appears to be activated under strict anoxic conditions and involves reduction of nitrate to ammonia using reductant generated by the catabolic oxidation of ethanol (the donor of electrons) to acetate, which is coupled to SLP. As shown in Figure 7, the ethanol is oxidized to acetaldehyde by an alcohol dehydrogenase (designated Ald), which is converted to acetyl-CoA by acetaldehyde dehydrogenase (AddA). The acetyl-CoA is then converted to acetate and CoA, with the concomitant production of ATP by Ack (Zhou et al., 2001). Under hypoxic conditions the ethanol is oxidized to acetate and the electrons generated in the reaction are used to reduce nitrite to $\mathrm{N}_{2} \mathrm{O}$, which is excreted from cells (Zhou et al., 2001; Figure 7). Nitrate and nitrite reductases catalyze the reduction of nitrogen oxides to ammonia using $\mathrm{NADH}$ as the electron donor, and are assimilatory enzymes.

\section{$\mathrm{H}_{2}$ and $\mathrm{CO}_{2}$ production}

$\mathrm{H}_{2}$ and $\mathrm{CO}_{2}$ are generated in an ancestral anaerobic pathway that is present in many green algae. The generation of $\mathrm{H}_{2}$ in algae often serves as a redox valve. This pathway can be in chloroplasts, as in Chlamydomonas and other algae, in mitochondria-like organelles, as in the Stramenopiles, or in the hydrogenosomes of the amoebozoa, some opisthokonta and Excavata. $\mathrm{H}_{2}$ production is often associated with PFR activity, which oxidizes pyruvate to acetyl-CoA and $\mathrm{CO}_{2}$. Reduced ferredoxin transfers electrons to a hydrogenase that can convert protons and electrons into $\mathrm{H}_{2}$ (Figure 5B).

\section{METABOLITE PARTITIONING, ORGANELLE COMMUNICATION AND ITS EVOLUTION CARBON PARTITIONING BETWEEN ORGANELLES}

Glycolysis is the backbone of eukaryote carbon and energy metabolism, leading to the production of pyruvate, ATP, and NADH. Further metabolism of the pyruvate can occur in the cytosol, mitochondrion, or plastid. For some eukaryotic organisms fermentation occurs entirely in the cytosol; the organisms included in this group are the protistan parasites such as Giardia and Entamoeba (Müller, 1996). Fermentations can also occur partly in hydrogenosomes, as is the case for Trichomonas (Müller, 1993). Among animals, fermentation often entails malate dismutation, involving segments of the mitochondrial electron transport chain, as in the case of the anaerobic mitochondria of many marine invertebrates and parasitic worms (Tielens et al., 2002; Tielens and van Hellemond, 2009).

A number of metabolic reactions can occur in more than one compartment in the cell and some enzymes may be routed to more than one cellular location; one example of this is PFL, which appears to occur in both chloroplasts and mitochondria, but dual localizations of proteins is not uncommon in eukaryotes (Atteia et al., 2006; Martin, 2010; Müller et al., 2012). Examining the network of activities in Chlamydomonas exposed to anoxic conditions raises some fundamental questions; one very important question is "How can an entire metabolic pathway be transferred to a new compartment?" This issue is still far from being resolved and more detailed biochemical and evolutionary analyses are necessary. However, it is becoming evident that over evolutionary time, enzymes and pathway can readily undergo re-compartmentation 
among subcellular locations in the cell including the mitochondrion, cytosol, hydrogenosome, and chloroplast. Small changes in targeting sequences might result in mistargeting, which could explain how individual activities, as well as entire pathways are found in more than one cellular compartment (Martin, 2010).

\section{EVOLUTIONARY INSIGHTS}

This review presents information indicating that overall, the different groups of eukaryotic organisms share the same core pathways for hypoxic/anoxic energy metabolism. Although distinct mechanisms are used by obligate and facultative anaerobes, there is a certain set of enzymes consistently associated with fermentation metabolism among a variety of organisms ranging from the bacteria to algae, fungi, and metazoans. The heterofermentation that is associated with the algae differs from lactate or ethanol homofermentation that occurs in yeast and various multicellular organisms including plants and animals; fermentation patterns in Chlamydomonas show some similarities to mixed-acid fermentation, which is common in the enteric bacteria (Neidhardt et al., 1990). The Chlamydomonas genome appears to contain a complete (or near complete) spectrum of genes involved in anaerobic energy metabolism across all eukaryotes (Müller et al., 2012; Atteia et al., 2013). However, the ancestry of these genes, whether from single or multiple origins, remains to be established. Müller et al. (2012) in a recent review favor the hypothesis that many of the enzymes associated with anaerobic energy metabolism in eukaryotes share a common ancestor, which is supported by the finding that different eukaryotic lineages possess different subsets of the same ancestral collection of genes. Furthermore, if the various genes for anaerobic metabolism in protists were derived from multiple ancestral genes, then evidence for the lateral transfer of genes from multiple sources should be apparent. The fact that no eukaryotes perform sulfate reduction, ammonium oxidation, or methane oxidation suggests that the independent lateral transfer of anoxic pathway genes to eukaryotes is not a common occurrence. Instead, different lineages of eukaryotic anaerobes use distinct enzyme combinations selected from a limited core inventory of fermentative pathways. Although a common origin of these pathways is speculative at this point, Müller et al. (2012) observes that there is no pattern of lineage specific acquisition, and it remains unclear why alternative anoxic strategies are not widely observed in eukaryotes.

\section{REFERENCES}

Alam, K. Y., and Clark, D. P. (1989). Anaerobic fermentation balance of Escherichia coli as observed by in vivo nuclear magnetic resonance spectroscopy. J. Bacteriol. 171, 6213-6217.

Atteia, A., Adrait, A., Brugière, S., Tardif, M., van Lis, R., Deusch, O., et al. (2009). A proteomic survey of Chlamydomonas reinhardtii mitochondria sheds new light on the metabolic plasticity of the organelle and on the nature of the $\alpha$ proteobacterial mitochondrial ancestor. Mol. Biol. Evol. 26, 1533-1548.

Atteia, A., van Lis, R., Gelius-Dietrich, G., Adrait, A., Garin, J., Joyard, J., et al. (2006). Pyruvate formate-lyase and a novel route of eukaryotic ATP synthesis in Chlamydomonas mitochondria. J. Biol. Chem. 281, 9909 9918.

Atteia, A., van Lis, R., Tielens, A. G. M., and Martin, W. F. (2013). Anaerobic energy metabolism in unicellular photosynthetic eukaryotes. Biochim. Biophys. Acta 1827, 210-223.

Avison, M. B., Horton, R. E., Walsh, T. R., and Bennett, P. M. (2001). Escherichia coli CreBC is a global regulator of gene expression that responds to growth in minimal media. J. Biol. Chem. 276, 2695526961.

\section{CONCLUSION}

Chlamydomonas is a metabolically versatile organism that can perform photosynthetic $\mathrm{CO}_{2}$ fixation, aerobic respiration, and anaerobic fermentation. This alga has served as a model system to examine many aspects of photosynthetic metabolism and recently has been used in studies of anaerobic metabolism; these latter studies have shown that Chlamydomonas contains a large and complex repertoire of anaerobic enzymes that are distributed among the different compartments of the cell. Initial characterizations have demonstrated that Chlamydomonas has flexible, mixed-acid fermentation, with features common to bacterial-, plant-, and yeast-type fermentation. Many pathways and enzymes associated with fermentation metabolisms in this alga are just being defined, and there is almost nothing known about the mechanisms by which these pathways are regulated and the trafficking of fermentation products among the different compartments in the cell. In general, photosynthetic algae appear to have a broad inventory of fermentative enzymes and, based on evidence discussed in this review, it appears that anaerobic respiration among eukaryotic algae is comparatively rare while anaerobic fermentation is widespread. Most enzymes for fermentative metabolism in the algae, often inferred from genomic and metabolic studies, have not been characterized biochemically. Expression patterns of genes encoding these enzymes and the biochemical properties of these enzymes and pathways need further characterization in a broader spectrum of algal systems. In addition, the diversity of end products that the various algae can synthesize during anaerobic fermentation is still mostly unknown. This information will be critical for developing a clear understanding of the metabolic diversity both within and among the different algal groups and the ways in which fermentation pathways have evolved and are shaped by environmental conditions. Finally, fermentation metabolism in the algae appears to represent a significant ecological component of carbon flux in soils (and sediments) that has a strong impact on its content of organic acids, alcohols, and $\mathrm{H}_{2}$; more focus on fermentation in the future is likely to unmask a relatively unexplored aspect of carbon cycling in the environment.

\section{ACKNOWLEDGMENT}

The work reported here was supported by the Department of Energy, Grant No. DE-FG02-12ER16338.

Bailey-Serres, J., and Chang, R. (2005). Sensing and signalling in response to oxygen deprivation in plant cells and other organisms. Ann. Bot. 96, 507-518.

Bailey-Serres, J., Fukao, T., Gibbs, D. J. Holdsworth, M. J., Lee, S. C., Licausi, F., et al. (2012). Making sense of low oxygen sensing. Trends Plant Sci. 17, 129-123.

Bailey-Serres, J., and Voesenek, L. A. C. J. (2008). Flooding stress: acclimations and genetic diversity. Annu. Rev Plant Biol. 59, 313-339.

Ball, S. (1998). "Regulation of starch biosynthesis," in The Molecular Biology of Chloroplasts and Mitochondria in Chlamydomonas,
Vol. 7, eds J. D. Rochaix, M. Goldschmiidt-Clermont, and S. Merchant (Dordrecht: Kluwer Academic Publishers), 549-567.

Ballantyne, J. S. (2004). Mitochondria: aerobic and anaerobic design - lessons from molluscs and fishes. Comp. Biochem. Physiol. B Biochem. Mol. Biol. 139, 461-467.

Beh, M., Strauss, G., Huber, R., Stetter, K. O., and Fuchs, G. (1993). Enzymes of the reductive citric acid cycle in the autotrophic eubacterium Aquifex pyrophilus and in the archaebacterium Thermoproteus neutrophilus. Arch. Microbiol. 160, 306-311. 
Belaich, A., and Belaich, J. P. (1976). Microcalorimetric study of the anaerobic growth of Escherichia coli: growth thermograms in a synthetic medium. J. Bacteriol. 125, $14-18$.

Ben-Amotz, A. (1975). Adaptation of the unicellular alga Dunaliella parva to a saline environment. J. Phycol. 11, 50-55.

Benemann, J. R., Berenson, J. A., Kaplan, N. O., and Kamen, M. D. (1973). Hydrogen evolution by a chloroplastferredoxin-hydrogenase system. Proc. Natl. Acad. Sci. U.S.A. 70, 2317-2320.

Boxma, B., Voncken, F., Jannink, S., Van Alen, T., Akhmanova, A., Van Weelde, S. V. H., et al. (2004). The anaerobic chytridiomycete fungus Piromyces sp. E2 produces ethanol via pyruvate:formate lyase and an alcohol dehydrogenase E. Mol. Microbiol. 51, 1389-1399.

Brocker, C., Vasiliou, M., Carpenter, S., Carpenter, C., Zhang, Y., Wang, X., et al. (2012). Aldehyde dehydrogenase (ALDH) superfamily in plants: gene nomenclature and comparative genomics. Planta 237, 189-210.

Brown, T. D. K., Jones-Mortimer, M. C., and Kornberg, H. L. (1977). The enzymic interconversion of acetate and acetyl-coenzyme A in Escherichia coli. J. Gen. Microbiol. 102, 327-336.

Buchanan, B. B., and Arnon, D. I. (1990). A reverse KREBS cycle in photosynthesis: consensus at last. Photosynth. Res. 24, 47-53.

Bunch, P. K., Mat-Jan, F., Lee, N., and Clark, D. P. (1997). The IdhA gene encoding the fermentative lactate dehydrogenase of Escherichia coli. Microbiology 143, 187-195.

Burgess, S. J., Tredwell, G., Molnar, A., Bundy, J. G., and Nixon, P. J. (2012). Artificial microRNA-mediated knockdown of pyruvate formate lyase (PFL1) provides evidence for an active 3hydroxybutyrate production pathway in the green alga Chlamydomonas reinhardtii. J. Biotechnol. 162, 57-66.

Burnett, L. E. (1997). The challenges of living in hypoxic and hypercapnic aquatic environments. Am. Zool. 37, 633-640.

Catalanotti, C., Dubini, A., Subramanian, V., Yang, W., Magneschi, L., Mus, F., et al. (2012). Altered fermentative metabolism in Chlamydomonas reinhardtii mutants lacking pyruvate formate lyase and both pyruvate formate lyase and alcohol dehydrogenase. Plant Cell 24, 692-707.

Chang, D. E., Shin, S., Rhee, J. S., and Pan, J. G. (1999). Acetate metabolism in a pta mutant of Escherichia coli W3100: importance of maintaining acetyl coenzyme A flux for growth and survival. J. Bacteriol. 181, 66566663.

Charon, M. H., Volbeda, A., Chabrière, E., Pieulle, L., and FontecillaCamps, J. C. (1999). Structure and electron transfer mechanism of pyruvate: ferredoxin oxidoreductase. Curr. Opin. Struct. Biol. 9, 663-669.

Chen, C., and Gibbs, M. (1992a). Coupling of carbon dioxide fixation to the oxyhydrogen reaction in the isolated chloroplast of Chlamydomonas reinhardtii. Plant Physiol. 100, 13611365.

Chen, C., and Gibbs, M. (1992b). Some enzymes and properties of the reductive carboxylic acid cycle are present in the green alga Chlamydomonas reinhardtii F-60. Plant Physiol. 98, 535-539.

Chochois, V., Dauvillee, D., Beyly, A., Tolleter, D., Cuine, S., Timpano, H., et al. (2009). Hydrogen production in Chlamydomonas: photosystem IIdependent and -independent pathways differ in their requirement for starch metabolism. Plant Physiol. 151, 631-640.

Clark, D. P. (1989). The fermentation pathways of Escherichia coli. FEMS Microbiol. Rev. 63, 223-234.

Cournac, L., Redding, K., Ravenel, J., Rumeau, D., Josse, E. M., Kuntz, M., et al. (2000). Electron flow between photosystem II and oxygen in chloroplasts of photosystem I-deficient algae is mediated by a quinol oxidase involved in chlororespiration. J. Biol. Chem. 275, $17256-$ 17262.

Danovaro, R., Dell'Anno, A., Pusceddu, A., Gambi, C., Heiner, I., and Kristensen, R. M. (2010). The first metazoa living in permanently anoxic conditions. BMC Biol. 8:30. doi: 10.1186/1741-7007-8-30

Dauvillee, D., Colleoni, C., Mouille, G., Buleon, A., Gallant, D. J., Bouchet, B., et al. (2001a). Two loci control phytoglycogen production in the monocellular green alga Chlamydomonas reinhardtii. Plant Physiol. 125, 1710 1722.

Dauvillee, D., Colleoni, C., Mouille, G., Morell, M. K., d'Hulst, C., Wattebled, F., etal. (2001b). Biochemical characterization of wild-type and mutant isoamylases of Chlamydomonas reinhardti supports a function of the multimeric enzyme organization in amylopectin maturation. Plant Physiol. 125 1723-1731.

Dent, R. M., Haglund, C. M., Chin, B. L., Kobayashi, M. C., and Niyogi, K. K. (2005). Functional genomics of eukaryotic photosynthesis using insertional mutagenesis of Chlamydomonas reinhardtii. Plant Physiol. 137, 545-556.

Dien, B. S., Cotta, M. A., and Jeffries, T. W. (2003). Bacteria engineered for fuel ethanol production: current status. Appl. Microbiol. Biotechnol. 63 258-266.

Dittrich, C. R., Bennett, G. N., and San, K. Y. (2005). Characterization of the acetate-producing pathways in Escherichia coli. Biotechnol. Prog. 21, 1062-1067.

Dubini, A., Mus, F., Seibert, M., Grossman, A. R., and Posewitz, M. C. (2009). Flexibility in anaerobic metabolism as revealed in a mutant of Chlamydomonas reinhardtii lacking hydrogenase activity. J. Biol. Chem. 284, 7201-7213.

Edwards, M. R., Gilroy, F. V., Jimenez, B. M., and O'Sullivan, W. J. (1989) Alanine is a major end product of metabolism by Giardia lamblia: a proton nuclear magnetic resonance study. Mol. Biochem. Parasitol. 37, 19-26.

Evans, M. C., Buchanan, B. B., and Arnon, D. I. (1966). A new ferredoxin-dependent carbon reduction cycle in a photosynthetic bacterium. Proc. Natl. Acad. Sci. U.S.A. 55, 928-934.

Fukuda, W., Ismail, Y. S., Fukui, T., Atomi, H., and Imanaka, T. (2005). Characterization of an archaeal malic enzyme from the hyperthermophilic archaeon Thermococcus kodakaraensis KOD1. Archaea 1, 293-301.

Gaffron, H. (1944). Photosynthesis, photoreduction and dark reduction of carbon dioxide in certain algae. Biol. Rev. Cambridge Philos. Soc. 19, 1-20.

Gaffron, H., and Rubin, J. (1942). Fermentative and photochemical production of hydrogen in algae. J. Gen. Physiol. 2, 219-240.

Gfeller, R. P., and Gibbs, M. (1984). Fermentative metabolism of Chlamydomonas reinhardtii: I. Analysis of fermentative products from starch in dark and light. Plant Physiol. 75, 212-218.

Gfeller, R. P., and Gibbs, M. (1985). Fermentative metabolism of Chlamydomonas reinhardtii: II. Role of plastoquinone. Plant Physiol. 77, 509-511.
Ghirardi, M. L., Maness, P. C., and Seibert, M. (2008). "Photobiological methods of renewable hydrogen production," in Solar Generation of Hydrogen, eds $\mathrm{K}$. Rajeshwar, R. McConnell, and S. Licht (New York, NY: Springer), 229-271.

Ghirardi, M. L., Posewitz, M. C., Maness, P. C., Dubini, A., Yu, J., and Seibert, M. (2007). Hydrogenases and hydrogen photoproduction in oxygenic photosynthetic organisms. Annu. Rev. Plant. Biol. 58, 71-91.

Ghirardi, M. L., Togasaki, R. K., and Seibert, M. (1997). Oxygen sensitivity of algal $\mathrm{H}_{2}$-production. Appl. Biochem. Biotechnol. 63, 141-151.

Ghirardi, M. L., Zhang, L., Lee, J. W., Flynn, T., Seibert, M., Greenbaum, E., et al. (2000). Microalgae: a green source of renewable $\mathrm{H}_{2}$. Trends Biotechnol. 18, 506-511.

Gibbs, J., and Greenway, H. (2003). Review: mechanisms of anoxia tolerance in plants. I. Growth, survival and anaerobic catabolism. Funct. Plant Biol. 30, 1-47.

Gibbs, M., Gfeller, R. P., and Chen, C. (1986). Fermentative metabolism of Chlamydomonas reinhardtii: III. Photoassimilation of acetate. Plant Physiol. 82, 160-166.

Godman, J. E., Molnar, A., Baulcombe, D. C., and Balk, J. (2010). RNA silencing of hydrogenase(-like) genes and investigation of their physiological roles in the green alga Chlamydomonas reinhardtii. Biochem J. 431, 345-351.

Gonzalez-Ballester, D., Pootakham, W., Mus, F., Yang, W., Catalanotti, C., Magneschi, L., et al. (2011). Reverse genetics in Chlamydomonas: a platform for isolating insertional mutants. Plant Methods 7, 24.

Gottschalk, G. (1985). Bacterial Metabolism, 2nd Edn. New York: Springer-Verlag.

Gray, C. T., and Gest, H. (1965). Biological formation of molecular hydrogen. Science. 148, 186-192.

Greenbaum, E. (1982). Photosynthetic hydrogen and oxygen production: kinetic studies. Science 215, 291-293.

Grieshaber, M. K., Hardewig, I., Kreutzer, U., and Portner, H. O. (1994). Physiological and metabolic responses to hypoxia in invertebrates. Rev. Physiol. Biochem. Pharmacol. 125, 43-147. 
Grossman, A. R., Catalanotti, C., Yang, W., Dubini, A., Magneschi, L., Subramanian, V., et al. (2011). Multiple facets of anoxic metabolism and hydrogen production in the unicellular green alga Chlamydomonas reinhardtii. New Phytol. 190 , 279-288.

Grossman, A. R., Croft, M., Gladyshev, V. N., Merchant, S. S. Posewitz, M. C., Prochnik, S., et al. (2007). Novel metabolism in Chlamydomonas through the lens of genomics. Curr. Opin. Plant. Biol. 10, 190-119.

Gupta, S., and Clark, D. P. (1989). Derivatives of Escherichia coli lacking both alcohol dehydrogenase and phosphotransacetylase grow anaerobically by lactate fermentation. J. Bacteriol. 171, 3650-3655.

Hahm, D. H., Pan, J. G., and Rhee, J. S. (1994). Characterization and evaluation of a pta(phosphotransacetylase) negative mutant of Escherichia coli HZB101 as a production host of foreign lipase. Appl. Microbiol. Biotechnol. 42, 100-107.

Happe, T., Mosler, B., and Naber, J. D. (1994). Induction, localization and metal content of hydrogenase in the green alga Chlamydomonas reinhardtii. Eur. J. Biochem. 222, 769-774.

Happe, T., and Naber, J. D. (1993). Isolation, characterization and $\mathrm{N}$-terminal amino acid sequence of hydrogenase from the green alga Chlamydomonas reinhardtii. Eur. J. Biochem. 214, 475-481.

Hemschemeier, A., and Happe, T. (2005). The exceptional photofermentative hydrogen metabolism of the green alga Chlamydomonas reinhardtii. Biochem. Soc. Trans. 33, 39-41.

Hemschemeier, A., Jacobs, J., and Happe, T. (2008). Biochemical and physiological characterization of the pyruvate formate-lyase PFL1 of Chlamydomonas reinhardtii, a typically bacterial enzyme in a eukaryotic alga. Eukaryot. Cell 7, 518-526.

Hoffmeister, M., Piotrowski, M., Nowitzki, U., and Martin, W. (2005). Mitochondrial trans-2-enoyl-CoA reductase of wax ester fermentation from Euglena gracilis defines a new family of enzymes involved in lipid synthesis. J. Biol. Chem. 280, 4329-4338.

Inui, H., Miyatake, K., Nakano, Y., and Kitaoka, S. (1982). Wax ester fermentation in Euglena gracilis. FEBS Lett. 150, 89-93.
Jewson, D. H., Lowry, S. F., and Bowen, R. (2006). Co-existence and survival of diatoms on sand grains. Eur. J. Phycol. 41, 131-146.

Kakuda, H., Hosono, K., Shiroishi, K., and Ichihara, S. (1994). Identification and characterization of the ackA (acetate kinase A)-pta (phosphotransacetylase) operon and complementation analysis of acetate utilization by an ackA-pta deletion mutant of Escherichia coli. J. Biochem. 116, 916-922.

Kamp, A., de Beer, D., Nitsch, J. L., Lavik, G., and Stief, P. (2011). Diatoms respire nitrate to survive dark and anoxic conditions. Proc. Natl. Acad. Sci. U.S.A. 14 5649-5654.

Kessler, E. (1974). "Hydrogenase, photoreduction and anaerobic growth," in Algal Physiology and Biochemistry, ed. W. D. P. Steward (Berkeley: University of California Press/Blackwell Scientific Publications Ltd), 456-473.

Kirch, H. H., Bartels, D., Wei, Y., Schnable, P. S., and Wood, A. J. (2004). The ALDH gene superfamily of Arabidopsis. Trends Plant Sci. 9,8 .

Kirch, H. H., Schlingensiepen, S., Kotchoni S, Sunkar, R., and Bartels, D. (2005). Detailed expression analysis of selected genes of the aldehyde dehydrogenase (ALDH) gene superfamily in Arabidopsis thaliana. Plant Mol. Biol. 57, 315-332.

Klein, U., and Betz, A. (1978). Fermentative metabolism of hydrogen-evolving Chlamydomonas moewusii. Plant Physiol. 61, 953-956.

Kosourov, S., Patrusheva, E., Ghirardi, M. L., Seibert, M., and Tsygankov, A. (2007). A comparison of hydrogen photoproduction by sulfur-deprived Chlamydomonas reinhardtii under different growth conditions. J. Biotechnol. 128, 776-787.

Kosourov, S., Seibert, M., and Ghirardi, M. L. (2003). Effects of extracellular $\mathrm{pH}$ on the metabolic pathways in sulfur-deprived, $\mathrm{H}_{2}$-producing Chlamydomonas reinhardtii cultures. Plant Cell Physiol. 44, 146-155.

Kreuzberg, K. (1984). Starch fermentation via formate producing pathway in Chlamydomonas reinhardtii, Chlorogonium elongatum and Chlorella fusca. Physiol. Plant. 61, 87-94.

Kreuzberg, K., Klöck, G., and Grobheiser, D. (1987). Subcellular distribution of pyruvate-degrading enzymes in Chlamydomonas reinhardtii studied by an improved protoplast fractionation procedure. Physiol. Plant. 69, 481-488.

Lilly, J. W., Maul, J. E., and Stern, D. B. (2002). The Chlamydomonas reinhardtii organellar genomes respond transcriptionally and post-transcriptionally to abiotic stimuli. Plant Cell 14, 2681-2706.

Lindmark, D. G., and Müller, M. (1973). Hydrogenosome, a cytoplasmic organelle of the anaerobic flagellate Tritrichomonas foetus, and its role in pyruvate metabolism. J. Biol. Chem. 248, 7724-7728.

Lomstein, E., Jensen, M. H., and Sørensen, J. (1990). Intracellular $\mathrm{NH} 4+$ and NO3- pools associated with deposited phytoplankton in a marine sediment (Aarhus Bight, Denmark). Mar. Ecol. Prog. Ser. 61, 97-105.

Magneschi, L., Catalanotti, C., Subramanian, V., Dubini, A., Yang, W. Mus, F., et al. (2012). A mutant in the $\mathrm{ADH} 1$ gene of Chlamydomonas reinhardtii elicits metabolic restructuring during anaerobiosis. Plant Physiol. 158, 1293-1305.

Maione, T. E., and Gibbs, M. (1986a). Association of the chloroplastic respiratory and photosynthetic electron transport chains of Chlamydomonas reinhardii with photoreduction and the oxyhydrogen reaction. Plant Physiol. 80, 364-368.

Maione, T. E., and Gibbs, M. (1986b). Hydrogenase-mediated activities in isolated chloroplasts of Chlamydomonas reinhardii. Plant Physiol. 80 , 360-363.

Martin, W. (2010). Evolutionary origins of metabolic compartmentation in eukaryotes. Philos. Trans. R. Soc. Lond. B Biol. Sci. 365, 847-855.

Mat-Jan, F., Alam, K. Y., and Clark, D. P. (1989). Mutants of Escherichia coli deficient in the fermentative lactate dehydrogenase. J. Bacteriol. 171, 342-348.

Maul, J. E., Lilly, J. W., Cui, L., de Pamphilis, C. W., Miller, W. Harris, E. H., et al. (2002). The Chlamydomonas reinhardtii plastid chromosome: islands of genes in a sea of repeats. Plant Cell 14, 2659-2679.

Melis, A., and Happe, T. (2001). Hydrogen production. Green algae as a source of energy. Plant Physiol. 127, 74-748.

Melis, A., and Happe, T. (2004). Trails of green alga hydrogen research
- from Hans Gaffron to new frontiers. Photosynth. Res. 80, 401-409.

Melis, A., Seibert, M., and Ghirardi, M. L. (2007). Hydrogen fuel production by transgenic microalgae. Adv. Exp. Med. Biol. 616, 110-121.

Melis, A., Zhang, L., Forestier, M., Ghirardi, M. L., and Seibert, M. (2000). Sustained photobiological hydrogen gas production upon reversible inactivation of oxygen evolution in the green alga Chlamydomonas reinhardtii. Plant Physiol. 122, 127-136.

Merchant, S. S., Prochnik, S. E., Vallon, O., Harris, E. H., Karpowicz, S. J., Witman, G. B., et al. (2007). The Chlamydomonas genome reveals the evolution of key animal and plant functions. Science 318, 245-250.

Meuser, J. E., Ananyev, G., Wittig, L. E., Kosourov, S., Ghirardi, M. L., Seibert, M., et al. (2009). Phenotypic diversity of hydrogen production in chlorophycean algae reflects distinct anaerobic metabolisms. J. Biotechnol. 142, 21-30.

Meuser, J. E., Boyd, E. S., Ananyev, G., Karns, D., Radakovits, R., Narayana Murthy, U. M., et al. (2011). Evolutionary significance of an algal gene encoding an [FeFe]hydrogenase with F-domain homology and hydrogenase activity in Chlorella variabilis NC64A. Planta 234, 829-843.

Meuser, J. E., D’Adamo, S., Jinkerson, R. E., Mus, F., Yang, W., Ghirardi, M. L., et al. (2012). Genetic disruption of both Chlamydomonas reinhardtii [FeFe]-hydrogenases: insight into the role of HYDA2 in $\mathrm{H}_{2}$ production. Biochem. Biophys. Res. Commun. 417, 704-709.

Miura, Y. (1995). Hydrogen production by biophotolysis based on marine microalgal photosynthesis. Process Biochem. 30, 1-7.

Morozkina, E. V., and Kurakov, A. V. (2007). Dissimilatory nitrate reduction in fungi under conditions of hypoxia and anoxia: a review. Appl. Biochem. Microbiol. 43, 607-613.

Morsy, F. M. (2011). Acetate versus sulfur deprivation role in creating anaerobiosis in light for hydrogen production by Chlamydomonas reinhardtii and Spirulina platensis: two different organisms and two different mechanisms. Photochem. Photobiol. 87, 137-142.

Mulder, D. W., Shepard, E. M., Meuser, J. E., Joshi, N., King, P. W., Posewitz, M. C., et al. (2011). Insights into 
[FeFe]-hydrogenase structure, mechanism, and maturation. Structure 19, 1038-1052.

Müller, M. (1993). The hydrogenosome. J. Gen. Microbiol. 139, 2879-2889.

Müller, M. (1996). “Energy metabolism of amitochondriate protists, an evolutionary puzzle," in Christian Gottfried EhrenbergFestschrift anläßlich der 14. Wissenschaftlichen Jahrestagung der Deutschen Gesellschaft für Protozoologie, 9-11 Marz 1995 in Delitzsch (Sachsen), eds M. Schlegel and K. Hausmann (Leipzig: Leipziger Universitätsverlag), 63-76

Müller, M. (2003). "Energy metabolism. Part 1: anaerobic protozoa," in Molecular Medical Parasitology, eds J. J. Marr, T. W. Nilsen, and R. W. Komuniecki (Amsterdam: Academic Press) 125-139.

Müller, M., Mentel, M., van Hellemond, J. J., Henze, K., Woehle, C., Gould, S. B., et al. (2012). Biochemistry and evolution of anaerobic. Energy metabolism in eukaryotes. Microbiol. Mol. Biol. Rev. 76, 444.

Mus, F., Cournac, L., Cardettini, V., Caruana, A., and Peltier, G. (2005). Inhibitor studies on non-photochemical plastoquinone reduction and $\mathrm{H}_{2}$ photoproduction in Chlamydomonas reinhardtii. Biochim. Biophys. Acta 1708, 322-332.

Mus, F., Dubini, A., Seibert, M., Posewitz, M. C., and Grossman, A. R. (2007). Anaerobic acclimation in Chlamydomonas reinhardtii: anoxic gene expression, hydrogenase induction, and metabolic pathways. J. Biol. Chem. 282, 25475-25486.

Neidhardt, F. C., Ingraham, J. L., and Schaechter, M. (1990). Physiology of the Bacterial Cell. Sunderland, MA: Sinauer.

Ohta, S., Miyamoto, K., and Miura, Y. (1987). Hydrogen evolution as a consumption mode of reducing equivalents in green algal fermentation. Plant Physiol. 83, 1022-1026.

Peters, J. W., Lanzilotta, W. N., Lemon, B. J., and Seefeldt, L. C. (1998). X-ray crystal structure of the Fe-only hydrogenase (CpI) from Clostridium pasteurianum to 1.8 angstrom resolution. Science 282, 1853-1858.

Philipps, G., Krawietz, D., Hemschemeier, A., and Happe, T. (2011). A pyruvate formate lyase-deficient Chlamydomonas reinhardtii strain provides evidence for a link between fermentation and hydrogen production in green algae. Plant J. 66 330-340.

Pietrzak, S. M., and Saz, H. J. (1981). Succinate decarboxylation to propionate and the associated phosphorylation in Fasciola hepatica and Spirometra mansonoides. Mol. Biochem. Parasitol. 3, 61-70.

Pootakham, W., Gonzalez-Ballester, D., and Grossman, A. R. (2010). Identification and regulation of plasma membrane sulfate transporters in Chlamydomonas. Plant Physiol. 153, 1653-1668.

Posewitz, M. C., King, P. W., Smolinski, S. L., Zhang, L., Seibert, M., and Ghirardi, M. L. (2004). Discovery of two novel radical $S$-adenosyl methionine proteins required for the assembly of an active [Fe] hydrogenase. J. Biol. Chem. 279, 25711-25720.

Pronk, J. T., Steensmays, H. Y., and Van Dijkent, J. P. (1996). Pyruvate metabolism in Saccharomyces cerevisiae. Yeast 12, 1607-1633.

Ragsdale, S. W. (2003). Pyruvate ferredoxin oxidoreductase and its radical intermediate. Chem. Rev. 103, 2333-2346.

Reeves, R. E. (1968). A new enzyme with the glycolytic function of pyruvate kinase. J. Biol. Chem. 243, 3202-3204.

Risgaard-Petersen, N., Langezaal, A. M., Ingvardsen, S., Schmid, M. C., Jetten, M. S. M., Op den Camp, H. J. M., et al. (2006). Evidence for complete denitrification in a benthic foraminifer. Nature 443, 93-96.

Roberts, J. K. M., Chang, K., Webster, C., Callis, J., and Walbot, V. (1989). Dependence of ethanolic fermentation, cytoplasmic $\mathrm{pH}$ regulation, and viability on the activity of alcohol dehydrogenase in hypoxic maize root tips. Plant Physiol. 89, 1275-1278.

Rose, I. A., Grunberg-Manago, M., Korey, S. R., and Ochoa, S. (1954). Enzymatic phosphorylation of acetate. J. Biol. Chem. 211, 737756.

Russell, G. K., and Gibbs, M. (1968). Evidence for the participation of the reductive pentose phosphate cycle in photoreduction and the oxyhydrogen reaction. Plant Physiol. 43, 649-652.

Sawers, G., and Watson, G. (1998). A glycyl radical solution: oxygen-dependent interconversion of pyruvate formate-lyase. Mol. Microbiol. 29, 945-954.

Schauder, R., Widdel, F., and Fuchs, G. (1987). Carbon assimilation pathways in sulfate-reducing bacteria. II. Enzymes of a reductive citric acid cycle in the autotrophic Desulfobacter hydrogenophilus. Arch. Microbiol. 148, 218-225.

Sweetlove, L. J., Beard, K. F., NunesNesi, A., Fernie, A. R., and Ratcliffe, R. G. (2010). Not just a circle: flux modes in the plant TCA cycle. Trends Plant Sci. 15, 462-470.

Takasaki, K., Shoun, H., Yamaguchi, M., Takeo, K., Nakamura, A., Hoshino, T., et al. (2004). Fungal ammonia fermentation, a novel metabolic mechanism that couples the dissimilatory and assimilatory pathways of both nitrate and ethanol. Role of acetyl CoA synthetase in anaerobic ATP synthesis. J. Biol. Chem. 279, 12414-12420.

Tarmy, E. M., and Kaplan, N. O. (1968). Kinetics of Escherichia coli B D-lactate dehydrogenase and evidence for pyruvate-controlled change in conformation. J. Biol. Chem. 243, 2587-2596.

Terashima, M., Specht, M., and Hippler, M. (2011). The chloroplast proteome: a survey from the Chlamydomonas reinhardtii perspective with a focus on distinctive features. Curr. Genet. 57, 151-168.

Terashima, M., Specht, M., Naumann, B., and Hippler, M. (2010). Characterizing the anaerobic response of Chlamydomonas reinhardtii by quantitative proteomics. Mol. Cell. Proteomics 9, 1514-1532.

Tielens, A. G. M., Rotte, C., van Hellemond, J. J., and Martin, W. (2002). Mitochondria as we don't know them. Trends Biochem. Sci. 27, 564-572.

Tielens, A. G. M., and van Hellemond, J. (1998). The electron transport chain in anaerobically functioning eukaryotes. Biochim. Biophys. Acta 1365 71-78.

Tielens, A. G. M., and van Hellemond, J. J. (2009). Surprising variety in energy metabolism within Trypanosomatidae. Trends Parasitol. 25 , 482-490.

Tucci, S., Vacula, R., Krajcovic, J., Proksch, P., and Martin, W. (2010). Variability of wax ester fermentation in natural and bleached Euglena gracilis strains in response to oxygen and the elongase inhibitor flufenacet. J. Eukaryot. Microbiol. 57, 63-69.

van den Thillart, G., van BergeHenegouwen, M., and Kesbeke,
F. (1983). Anaerobic metabolism of goldfish, Carassius auratus (L.): ethanol and $\mathrm{CO}_{2}$ excretion rates and anoxia tolerance at 20 , 10 and $5^{\circ} \mathrm{C}$. Comp. Biochem. Physiol. A Comp. Physiol. 76, 295-300.

van Dijken, J. P., and Scheffers, W. A. (1986). Redox balances in the metabolism of sugars by yeasts. (NAD $(\mathrm{H})$; $\mathrm{NADP}(\mathrm{H})$; glucose metabolism; xylose fermentation; ethanol; Crabtree effect; Custers effect). FEMS Microbiol. Rev. 32, 199-224.

Vanlerberghe, G. C., Feil, R., and Turpin, D. H. (1990). Anaerobic metabolism in the $\mathrm{N}$-limited green alga Selenastrum minutum: I. Regulation of carbon metabolism and succinate as a fermentation product. Plant Physiol. 94, 1116-1123.

Vanlerberghe, G. C., Horsey, A. K., Weger, H. G., and Turpin, D. H. (1989). Anaerobic carbon metabolism by the tricarboxylic acid cycle: evidence for partial oxidative and reductive pathways during dark ammonium assimilation. Plant Physiol. 91, 1551-1557.

Varenne, S., Casse, F., Chippanx, M., and Pascal, M. C. (1975). A mutant of Escherichia coli deficient in pyruvate formate lyase. Mol. Gen. Genet. 141, 181-184.

van Warde, A., Van den Thillart, G., and Verhagen, M. (1993). "Ethanol formation and $\mathrm{pH}$ regulation in fish," in Surviving Hypoxia, eds P. W. Hochachka, P. L. Lutz, T. Sick, M. Rosenthal, and G. van den Thillart (Boca Raton: CRC Press), 157-170.

Wang, Z. X., Zhuge, J., Fang, H., and Prior, B. A. (2001). Glycerol production by microbial fermentation: a review. Biotechnol. Adv. 19, 201-223.

Wolfe, A. J. (2005). The acetate switch. Microbiol. Mol. Biol. Rev. 69, 12-50.

Woods, S. A., Schwartzbach, S. D., and Guest, J. R. (1988). Two biochemically distinct classes of fumarase in Escherichia coll. Biochim. Biophys. Acta 954, 14-26.

Yang, Y. T., Aristidou, A. A., San, K. Y., and Bennett, G. N. (1999). Metabolic flux analysis of Escherichia coli deficient in the acetate production pathway and expressing the Bacillus subtilis acetolactate synthase. Metab. Eng. 1, 26-34.

Yoon, K. S., Hille, R., Hemann, C., and Tabita, F. R. (1999). 
Rubredoxin from the green sulfur bacterium Chlorobium tepidum functions as an electron acceptor for pyruvate ferredoxin oxidoreductase. J. Biol. Chem. 274, 29772-29778.

Zabawinski, C., Van Den Koornhuyse, N., D'Hulst, C., Schlichting, R., Giersch, C., Delrue, B., etal. (2001). Starchless mutants of Chlamydomonas reinhardtii lack the small subunit of a heterotetrameric ADP-glucose pyrophosphorylase. J. Bacteriol. 183, 1069-1077.

Zhou, Z., Takaya, N., Sakairi, M.

A. C., and Shoun, H. (2001). Ammonia fermentation, a novel anoxic metabolism of nitrate by fungi. Arch. Microbiol. 175, 19-25.

Conflict of Interest Statement: The authors declare that the research was conducted in the absence of any commercial or financial relationships that could be construed as a potential conflict of interest.

Received: 01 March 2013; accepted: 02 May 2013; published online: 22 May 2013.

Citation: Catalanotti C, Yang W, Posewitz MC and Grossman AR (2013) Fermentation metabolism and its evolution in algae. Front. Plant Sci. 4:150. doi: 10.3389/fpls.2013.00150
This article was submitted to Frontiers in Plant Physiology, a specialty of Frontiers in Plant Science.

Copyright (C) 2013 Catalanotti, Yang, Posewitz and Grossman. This is an open-access article distributed under the terms of the Creative Commons Attribution License, which permits use, distribution and reproduction in other forums, provided the original authors and source are credited and subject to any copyright notices concerning any thirdparty graphics etc. 